\title{
Magnetic resonance imaging for lung cancer: a state-of-the-art review
}

\section{So Hyeon Bak ${ }^{1,2,}$, Chohee Kim ${ }^{1,}$, Chu Hyun Kim ${ }^{1, *}$, Yoshiharu Ohno ${ }^{3,4}$, Ho Yun Lee ${ }^{1,5}$}

\author{
${ }^{1}$ Department of Radiology and Center for Imaging Science, Samsung Medical Center, Sungkyunkwan University School of \\ Medicine, Seoul, Korea \\ ${ }^{2}$ Department of Radiology, School of Medicine, Kangwon National University, Chuncheon, Korea \\ ${ }^{3}$ Department of Radiology, Fujita Health University School of Medicine, Toyoake, Japan \\ ${ }^{4}$ Joint Research Laboratory of Advanced Medical Imaging, Fujita Health University School of Medicine, Toyoake, Japan \\ ${ }^{5}$ Department of Health Sciences and Technology, Samsung Advanced Institute for Health Sciences \& Technology (SAIHST), \\ Sungkyunkwan University, Seoul, Korea
}

Received: October 29, 2021

Revised: December 15, 2021

Accepted: January 11, 2022

Corresponding author:

Ho Yun Lee

Department of Radiology and

Center for Imaging Science,

Samsung Medical Center,

Sungkyunkwan University

School of Medicine, 81 Irwon-ro,

Gangnam-gu, Seoul 06351, Korea

Tel: +82-2-3410-2502

E-mail: hoyunlee96@gmail.com

*So Hyeon Bak, Chohee Kim, and Chu Hyun Kim contributed equally to this study as first authors.

\section{ABSTRACT}

Lung cancer is the leading cause of cancer-related deaths worldwide, and imaging techniques such as chest radiography, computed tomography (CT), positron emission tomography (PET), and magnetic resonance imaging (MRI) play an important role in its diagnosis, staging, treatment planning, post-operative surveillance, and treatment response evaluation. Pulmonary MRI can non-invasively visualize structural and functional abnormalities in the lungs without using ionizing radiation, although it has been suggested that it has less clinical utility than chest radiography, CT, and PET/CT for thoracic diseases, especially lung diseases. With recent advances related to MRI pulse sequences, pulmonary MRI has become practicable in an expanding number of clinical situations. This review article focuses on recent advances in MRI and discusses its clinical applications in the detection, diagnosis, staging, pre-operative evaluation, post-operative surveillance, and treatment response evaluation of lung cancer.

Keywords: Lung neoplasms; Magnetic resonance imaging; Solitary pulmonary nodule

\section{INTRODUCTION}

Lung cancer is a leading cause of cancer-related morbidity and mortality worldwide [1], and imaging techniques such as computed tomography (CT) and positron emission tomography (PET) play an important role in its diagnosis, staging, treatment planning, post-operative surveillance, and treatment response evaluation [2]. Although it has been suggested that magnetic resonance imaging (MRI) has less clinical utility for thoracic diseases than radiography, CT, and $\mathrm{PET} / \mathrm{CT}$, for certain specific indications, MRI has recently become more practicable owing to advances in post-processing software and analysis methods, magnetic resonance (MR) pulse sequences, multi-coil parallel imaging and acceleration methods, and the use of contrast 
media. Moreover, various functional and metabolic sequences and morphological sequences to enhance relaxation time differences introduced since $\mathbf{2 0 0 0}$ have been found to be of considerable clinical relevance in cancer as well as other diseases. Thus, MRI for thoracic diseases is currently an attractive research field and represents a new frontier in MRI technology. In this article, we review both basic and advanced MRI techniques and discuss their clinical applications for lung cancer.

\section{THORACIC MRI TECHNIQUES}

Paul Lauterbur, who received the 2003 Nobel Prize in Medicine with Peter Mansfield, developed the first MRI scanner in the 1970s. Inhomogeneity in magnetic susceptibility due to air and soft tissue interfaces within the lung, combined with motion and low intrinsic proton density, hinders the use of MRI in the lung parenchyma [3-11]. Moreover, differences in susceptibility to artifacts in the lung parenchyma and chest wall manifest as a dark line perpendicular to the frequency encoding direction. Therefore, thoracic MRI was initially considered less informative than CT for the assessment of lung parenchymal diseases and thoracic oncologic diseases in clinical practice $[4,6,8-33]$. Nonetheless, researchers have been trying to enhance the utility of MRI for lung cancer and mediastinal tumors and for pulmonary vascular diseases $[4$, 6,8-33].

\section{Traditional MRI for lung cancer}

In the early 1990s, spin echo (SE) sequences were used for clinical lung cancer MRI; however, reports published by the Radiologic Diagnostic Oncology Group concluded that MRI with non-electrocardiogram (ECG)-gated T1-weighted SE imaging had less utility than $\mathrm{CT}$ for tumor, lymph node, and metastasis (TNM) staging [34]. Since then, continuous and remarkable technical advancements have been made. Techniques such as turbo or fast SE and gradient-recalled-echo (GRE) sequences, fast GRE with short echo time (TE), in- and opposed phase T1-weighted GRE, T1- and T2-weighted, short inversion time inversion recovery (STIR), and turbo spin echo (TSE) with the half-Fourier single-shot method with and without black-blood have been used in routine clinical practice since the early 1990 s $[6,10,11,13,17,20,24-26,29]$. Diffusion-weighted imaging (DWI) has been used in combination with single-shot echo-planar imaging (EPI) sequences and the fat-suppression technique for oncologic evaluation since the early 2000s $[13,17,20,24-26,29]$. Therefore, almost all MRI sequences for thoracic oncological diseases were established by the mid-2000s. During the same period, the parallel imaging technique, as well as fast GRE with short TE or ultrashort TE (UTE) and contrast media were proposed for time-resolved (or 4D) contrast-enhanced (CE-) MR angiography, dynamic CE (DCE-) MRI, and DCE-perfusion MRI; assessments of these techniques have demonstrated that they are clinically relevant for the management of pulmonary nodules and masses and for TNM staging [6,10-13,16,17,20,22-26,28-31]. Since the mid-2000s, even newer techniques for dedicated thoracic MRI and whole-body MRI have been introduced and used for morphological and functional evaluation. Recently, a PET technique using ${ }^{18} \mathrm{~F}$-fluorodeoxyglucose (FDG) with MRI (FDG-PET/MRI or FDG-MR/PET) has been developed, and attempts have been made to evaluate MR-based and glucose metabolism-based information simultaneously [24]. Moreover, MRI techniques have started being used as molecular imaging tools $[35,36]$.

\section{Technical advances in MRI during the past decade}

The clinical availability of 3T MRI has increased. The highfield strength increased the signal-to-noise ratio (SNR) and resolution, which improved lesion detection; however, for the lungs, susceptibility and image distortion are more severe on 3 T MR than on 1.5 T MR images due to magnetic field inhomogeneity $[13,37,38]$. Fink et al. [37] showed that the imaging characteristics of different pulse sequences for lung MRI were similar at 1.5 and $3 \mathrm{~T}$, but that higher lesion contrast can be expected at $3 \mathrm{~T}$. In addition, T1-weighted 3D turbo field echo and T2-weighted triple-inversion black-blood TSE 3 T MRI allow the detection of clinically significant pulmonary nodules nearly as well as CT [39]. On the other hand, the performance of low-field MRI systems has been considered poor, with limited spatial resolution and low SNR [40]; nevertheless, Campbell-Washburn et al. [38] reported that a lowfield MRI system equipped with high-performance image technology could reduce distortion by reducing susceptibility and deliver excellent image quality because of improved field homogeneity.

Since the early 2000s, DWI has been applied as a form of MRI that measures the random Brownian motion of water molecules within a voxel of tissue. Diffusion is particularly useful in tumor characterization, $\mathrm{N}$ - and $\mathrm{M}$-stage evaluation, and therapeutic effect prediction [13,17,20,24-26,29,41-47]. Although the most commonly used technique relies on SE-EPI, non-EPI techniques such as fast advanced SE or TSE are also available and useful for lung cancer evaluation using high- 
field MR, especially $3 \mathrm{~T} M R$, systems to reduce image distortion and improve image quality and accuracy of apparent diffusion coefficient (ADC) measurements [48,49].

DWI allows the calculation of tissue $A D C$, a quantitative measure of tissue diffusivity, and enables the objective comparison of results for pulmonary mass characterization, $\mathrm{N}$ and $\mathrm{M}$-stage assessments, predicting the therapeutic effects of conservative therapy, and evaluating treatment response after chemotherapy in non-small cell lung cancer (NSCLC) $[13,17,20,24-26,29,41-47,49]$. However, signal attenuation on DWI at low b-values (e.g., 0 to $100 \mathrm{sec} / \mathrm{mm}^{2}$ ) arises not only from water diffusion in tissues, but also from microcirculation within the normal capillary network [41-53]. In 1986, Le Bihan et al. [54] termed the behavior of protons that display signal attenuation on DWI intravoxel incoherent motion (IVIM), and suggested that using more sophisticated approaches to describe signal attenuation in tissues with increasing b-values would enable the estimation of quantitative parameters that separately reflect tissue diffusivity and tissue microcapillary perfusion [55]. Using IVIM-based analysis, it is now possible to derive other quantitative indexes that describe tissue water diffusivity (slow component of diffusion), tissue perfusion (pseudo diffusion coefficient), and tissue perfusion fraction.

Spoiled 3D GRE sequences with different fat-suppression techniques-such as 3D volumetric interpolated breath-hold examination (VIBE; Siemens Healthineers, Erlangen, Germany), T1-weighted high-resolution isotropic volume examination (THRIVE; Philips Healthcare, Cambridge, MA, USA), and the fast and segmented 3D T1-weighted spoiled gradient echo sequence (Quick 3D, Canon Medical Systems, Otawara, Japan)-have replaced T1-weighted SE and TSE sequences for obtaining CE-T1-weighted images in lung cancer, and are in clinical use for nodule detection in thoracic MRI, TNM stage evaluations and recurrence assessments in whole-body MRI, and FDG-PET/MRI in NSCLC [56-59].

Since the mid-2010s, radial acquisition of k-space data from free induction decay has reduced TE to less than $200 \mu$ s, minimizing signal decay due to a short transverse relaxation time $\left(\mathrm{T} 2 / \mathrm{T} 2^{\star}\right)$. It has therefore been suggested that the development of UTE or zero TE sequences could be a game changer for thoracic MRI $[4,6,8-11,13,22,60-64]$, because they would allow for better visualization of endogenous lung parenchyma MR signal than with conventional short echo image sequences. MRI with UTE could also enable quantitative assessment of regional $\mathrm{T}^{*}$ values and morphological changes in pulmonary parenchymal diseases $[60,63]$. Therefore,
MRI with UTE could enable new morphological MRI assessments not only for thoracic oncology but also for other pulmonary diseases.

As a new molecular imaging method using magnetic fields equal to or higher than $3 \mathrm{~T}$, chemical exchange saturation transfer (CEST) imaging maps the chemical exchange between bulk water protons and exchangeable protons in small metabolites and macromolecules $[35,36,65,66]$. The most commonly studied signals in CEST imaging arise from the amide proton transfer signals of peptides and proteins, called amide proton transfer (APT) imaging. This new technique has been tested for nodule characterization, and its clinical potential has been suggested in a few studies $[35,36]$.

\section{CLINICAL APPLICATIONS OF THORACIC MRI}

\section{Lung nodule detection and lung cancer screening}

Since 2011, annual screenings using low-dose computed tomography (LDCT) have been performed worldwide, as this can reduce lung cancer mortality by $20 \%$ [67], with the CTbased Lung Imaging Reporting and Data System (LungRADS) being widely used for nodule assessment and subsequent management [68]; however, this increases radiation burden and can lead to unnecessary invasive procedures or complications, because LDCT has a high malignancy-related false-positive rate (23\%) [67].

MRI has been perceived to be inferior to $\mathrm{CT}$ in evaluating small nodules because of its sensitivity to cardiac and respiratory motion artifacts, very low $\mathrm{T}^{*}$ * values, lung magnetic field heterogeneity, and low proton density of the lung parenchyma [69]. However, techniques using three-dimensional GRE and UTE sequences and thin-section thicknesses (1 to $1.25 \mathrm{~mm}$ ) have shown detection rates of more than $90 \%$ for lung nodules ranging from 4 to $29 \mathrm{~mm}$ in diameter, which is at least as efficacious as standard- or reduced-dose thin-section CT for nodule detection [61,62]. Although study results have varied because of the use of different hardware and software settings, the ability of MRI to detect solid nodules was $57.1 \%$ for nodules smaller than $4 \mathrm{~mm}, 60 \%$ to $90 \%$ for nodules 5 to $8 \mathrm{~mm}$, and almost $100 \%$ for nodules $8 \mathrm{~mm}$ or larger [70-74]. MRI under the optimal conditions of successful breath-holds and reliable gating or triggering detected $90 \%$ of 3-mm nodules [75], and MRI with spiral UTE sequences had a $95 \%$ success rate regardless of nodule size [76]. Nodule detection rate using spiral UTE sequences was $>65 \%$ for non-solid nodules ( 3 to $20 \mathrm{~mm}$ ), > 75\% for part-solid nodules 
PRECISION AND FUTURE MEDICINE

MRI for lung cancer

Table 1. Results from prior publications regarding the diagnostic performance of various MRI sequences in terms of nodule detection and determination of malignancy

\begin{tabular}{|c|c|c|c|c|c|}
\hline \multirow{2}{*}{ Study } & \multirow{2}{*}{$\begin{array}{l}\text { Individuals/ } \\
\text { lesions }\end{array}$} & \multirow{2}{*}{$\begin{array}{l}\text { Lesion size } \\
(\mathrm{mm})\end{array}$} & \multirow{2}{*}{ Methods } & \multicolumn{2}{|c|}{ Diagnostic performance } \\
\hline & & & & Sensitivity (\%) & Specificity (\%) \\
\hline \multirow[t]{4}{*}{ Koyama et al. (2008) [70] } & $161 / 200$ & $10-30$ & Morphology and CNR & & \\
\hline & & & T1 SE & $84-88$ & $38-40$ \\
\hline & & & T2 TSE & $81-87$ & $38-49$ \\
\hline & & & STIR & $83-84$ & $55-61$ \\
\hline \multirow[t]{5}{*}{ Meier-Schroers et al. (2016) [73] } & $30 / 41$ & & Morphology and CNR & & \\
\hline & & $4-8$ & T2 FSE & $50-52.9$ & $77.8-76.2$ \\
\hline & & & $\mathrm{T} 2 \mathrm{MV}$ & $58.8-55.9$ & $94.1-83.3$ \\
\hline & & $\geq 8$ & T2 FSE & 100 & 95.8 \\
\hline & & & $\mathrm{T} 2 \mathrm{MV}$ & 100 & 100 \\
\hline \multirow[t]{6}{*}{ Dewes et al. (2016) [72] } & 54 & $2.1-71.2$ & Morphology & & \\
\hline & & & CAIPIRINHA-VIBE & & \\
\hline & & $<5$ & & $75.7-80$ & \\
\hline & & $5-10$ & & $85.7-89.2$ & \\
\hline & & $11-15$ & & 100 & \\
\hline & & $>15$ & & 100 & \\
\hline \multirow[t]{4}{*}{ Cieszanowski et al. (2016) [71] } & $54 / 113$ & $2-28$ & Morphology & & \\
\hline & & & VIBE & 69 & \\
\hline & & & T2 TSE & 49 & \\
\hline & & & T2 STIR & 45 & \\
\hline \multirow[t]{5}{*}{ Meier-Schroers et al. (2019) [74] } & $32 / 46$ & $\geq 6$ & Morphology and CNR & & \\
\hline & & & T2 STIR & $85-89$ & $92-94$ \\
\hline & & & $\mathrm{T} 2$ & $80-87$ & $93-96$ \\
\hline & & & bSSFP & $65-70$ & $96-98$ \\
\hline & & & 3D-T1 & $63-67$ & $96-100$ \\
\hline \multirow[t]{4}{*}{ Huang et al. (2021) [76] } & $120 / 165$ & $3-20$ & Morphology & & \\
\hline & & & VIBE & $55.2-84$ & $96.8-97.2$ \\
\hline & & & UTE free-breathing & $78.2-81.2$ & $98.9-99.5$ \\
\hline & & & UTE breath-hold & $75.2-77$ & 98.6-99.3 \\
\hline \multirow[t]{8}{*}{ Feng et al. (2021) [77] } & $82 / 256$ & $<30$ & Morphology & & False-positive \\
\hline & & Solid, $<6$ & PETRA & 64 & $2 / 30$ \\
\hline & & Solid, 6-8 & & 100 & $0 / 20$ \\
\hline & & Solid, $>8$ & & 100 & $0 / 32$ \\
\hline & & $\mathrm{PSN},<6$ & & 79 & $0 / 15$ \\
\hline & & PSN, $\geq 6$ & & 99 & $0 / 66$ \\
\hline & & $\mathrm{GGN},<6$ & & 47 & $4 / 15$ \\
\hline & & $\mathrm{GGN}, \geq 6$ & & 92 & $3 / 36$ \\
\hline
\end{tabular}

MRI, magnetic resonance imaging; CNR, contrast-to-noise ratio; SE, spin echo; TSE, turbo spin echo; STIR, short inversion time inversion recovery; FSE, fast spin echo; MV, multivane; CAIPIRINHA-VIBE, parallel imaging results in higher acceleration volumetric interpolated breath-hold examination; VIBE, volumetric interpolated breath-hold examination; bSSFP, balanced steady state free precession; UTE, ultrashort echo time; PETRA, pointwise encoding time reduction with radial acquisition; PSN, part-solid nodule; GGN, ground glass nodule. 
( 5 to $18 \mathrm{~mm}$ ), and $100 \%$ for nodule size $>16 \mathrm{~mm}$ [76]. MRI using the pointwise encoding time reduction with radial acquisition sequence on a 3 T system detected $72 \%$ and $94 \%$ of $<3-\mathrm{cm}$ ground glass and part-solid nodules, respectively (Table 1) $[70-74,76,77]$. Discrimination of attenuation of detected nodules by MRI indicated almost perfect agreement compared to that with CT [77]. The average risk of cancer in solid nodules smaller than $6 \mathrm{~mm}$ in high-risk patients is less than $1 \%$ [78]; as nodules $>8 \mathrm{~mm}$ require short-term follow-up or further evaluation according to the Lung-RADS [68], it is reasonable to evaluate the use of MRI to screen for lung cancer. In a recent study, Meier-Schroers et al. [79] compared LDCTand MRI-derived Lung-RADS categories in two screening rounds. Nodules from 224 participants were prospectively analyzed following the German Lung Cancer Screening Intervention Trial inclusion criteria using LDCT and T2, balanced T1, and DWI MRI sequences at 1.5 T. Nodule size detected us- ing MRI correlated significantly with the LDCT findings; MRI accurately detected $70 \%$ of solid nodules $<6 \mathrm{~mm}, 98 \%$ of solid nodules $\geq 6 \mathrm{~mm}$, and $72 \%$ sub-solid nodules $<20 \mathrm{~mm}$ in size (Fig. 1). Moreover, the MRI and CT Lung-RADS score correlated significantly, and nodules with a Lung-RADS score

Table 2. Lung-RADS scores assigned using MRI and LDCT

\begin{tabular}{lccc}
\hline Lung-RADS & $\begin{array}{c}\text { Baseline } \\
\text { MRI/LDCT }\end{array}$ & $\begin{array}{c}\text { Follow-up } \\
\text { MRI/LDCT }\end{array}$ & $\begin{array}{c}\text { Total } \\
\text { MRI/LDCT }\end{array}$ \\
\hline 1 & $137 / 123$ & $3 / 3$ & $140 / 126$ \\
2 & $56 / 72$ & $21 / 20$ & $77 / 92$ \\
3 & $12 / 11$ & $1 / 1$ & $12 / 13$ \\
$4 \mathrm{~A}$ & $12 / 13$ & $3 / 3$ & $16 / 15$ \\
$4 \mathrm{~B} / 4 \mathrm{X}$ & $6 / 6$ & $4 / 4$ & $10 / 10$ \\
\hline
\end{tabular}

Lung-RADS, Lung Imaging Reporting and Data System; MRI, magnetic resonance imaging; LDCT, low-dose computed tomography.
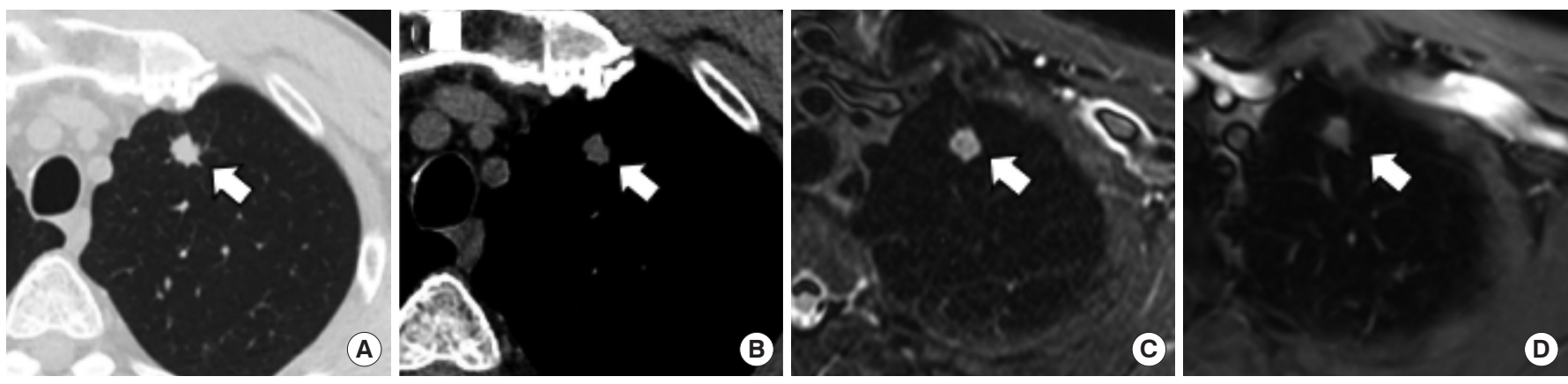

Fig. 1. A $10 \mathrm{~mm}$ solid nodule in the left upper lobe in a 58-year-old man. The nodule (arrows) was clearly visible using all magnetic resonance imaging (MRI) sequences and classified as Lung-RADS $4 \mathrm{X}$ because of a spiculated margin. (A) Computed tomography (CT) lung window, (B) CT soft tissue window, (C) MRI T2 short inversion time inversion recovery, and (D) MRI contrast-enhanced fat-saturated T1weighted images.
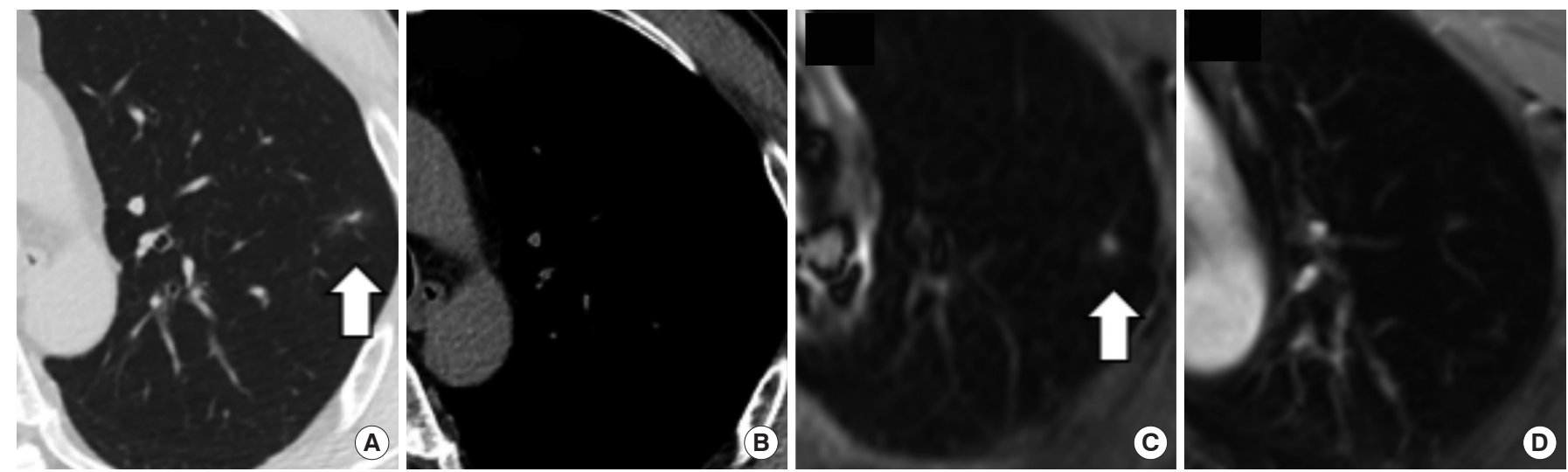

Fig. 2. A $12 \mathrm{~mm}$ sub-solid nodule in the left upper lobe (classified as Lung-RADS 2 based on magnetic resonance imaging [MRI] and computed tomography [CT]) in a 58-year-old man. This nodule (arrows) was only slightly hyperintense on T2-weighted sequence images and hardly detectable using contrast-enhanced fat-saturated T1-weighted imaging. (A) CT lung window, (B) CT soft tissue window, (C) MRI T2 short inversion time inversion recovery, and (D) MRI contrast-enhanced fat-saturated T1-weighted images. 
of 3 or more were never under-scored or missed using MRI (Fig. 2), although MRI-based Lung-RADS scores were overestimated in terms of size and presence of pulmonary vessel or streaky opacities, and underestimated for 4 to $5 \mathrm{~mm}$ solid nodules and sub-solid nodules smaller than $20 \mathrm{~mm}$ (Table 2). The early recall rate decreased from $13.8 \%$ at baseline to $1.9 \%$ during the second screening, consistent with the indicator of good quality based on hypothesized optimal recall for mammographic examinations (12\% to $14 \%$ ) [80].

Concerning false-positives in lung cancer screening using LDCT, another study that compared MRI and LDCT for lung nodule detection in a high-risk population reported a $5 \%$ false-positive rate using MRI [81], which was better compared to that in the first round of the National Lung Cancer Trial (23.3\%).

Thus, several studies show that lung MRI could be a potentially effective screening tool, with a performance comparable to that of LDCT, but with a lower false-positive rate and no radiation exposure.

\section{Lung nodule characterization}

Since pulmonary nodules are one of the most common chest imaging findings, it is important to differentiate between malignant and benign nodules. Although $\mathrm{CT}$ is the most widely used modality for pulmonary nodule evaluation, it relies on morphological examination and contrast enhancement, resulting in is high sensitivity (95\% to 100\%) but relatively low specificity (30\% to 58\%) [82]. PET/CT performed using the radiotracer ${ }^{18} \mathrm{FDG}$ is also a useful tool. It combines both metabolic and morphologic parameters for nodule characterization $[83,84]$; however, there are some disadvantages, such as non-detection of some well-differentiated pulmonary adenocarcinomas, misclassification of benign inflammatory nodules, high cost, and radiation exposure (Table 3) [85-87].
Numerous MRI sequences have been evaluated for pulmonary nodule characterization [28]. To date, DWI is considered the most useful tool in this regard-many studies have shown that cancerous lung nodules have significantly higher signals on DWI and lower signals on ADC maps than benign ones (sensitivity, $70 \%$ to $99 \%$; specificity, $66 \%$ to $97 \%$ ) $[42,88-93]$. Moreover, when efficacy was compared with that using ${ }^{18} \mathrm{FDG}$ in PET/CT, the results were satisfactory [88,93]. Table 4 shows the major study results regarding pulmonary nodule diagnosis using DWI. Image distortion remains a major limitation, but emerging techniques may be able to correct this. Correcting distortion using reverse-phase encoding diffusion-weighted $3 \mathrm{~T} \mathrm{PET/MRI} \mathrm{showed} \mathrm{satisfactory} \mathrm{results} \mathrm{in} \mathrm{reducing} \mathrm{ADC}$ value errors when evaluating lung tumors [94]. A few studies have attempted to evaluate the utility of DCE-MRI in diagnosing lung nodules with a focus on management, showing that DCE-MR indexes were useful in differentiating between solitary pulmonary nodules that necessitated further evaluation or treatment (malignant or actively infected) and nodules that did not (benign) $[95,96]$.

MRI has clear advantages in certain clinical situations, such as differentiating lung cancer from progressive massive fibrosis (PMF), tuberculomas, or obstructive pneumonia-when T2-weighted MRI was used to study PMF in 24 patients with coal workers' pneumoconiosis, signal intensity of PMF was low, whereas most lung cancer lesions showed intermediate or high signal intensity (Fig. 3) [97]. Tuberculoma lesions tend to have a more heterogeneous signal intensity than lung cancer lesions, and a higher percentage of tuberculosis lesions have hypo-intensity on T2-weighted images and hyperintensity on T1-weighted images [98]. CE imaging can differentiate tuberculomas from lung cancer, because tuberculomas frequently show a thin enhancing rim and a non-en-

Table 3. Advantages and disadvantages of MRI and PET/CT for lung nodule characterization

\section{MRI}

Advantages

Disadvantages

Provides both morphologic and functional imaging data

Possible combination of molecular imaging techniques

No radiation exposure

No need of iodinated contrast material

Lower spatial resolution

Image artifacts
$\mathrm{PET} / \mathrm{CT}$

Provides both metabolic and morphologic parameter data

Non-detection of certain well-differentiated pulmonary adenocarcinomas

Misclassification of benign inflammatory nodules

High cost

Radiation exposure

$\mathrm{MRI}$, magnetic resonance imaging; $\mathrm{PET} / \mathrm{CT}$, positron emission tomography/computed tomography. 
hancing central zone on post-contrast MRI, which correlates with the histological findings that tuberculomas have a fibrous peripheral capsule and epithelioid granulomas in the central zone [99].

MRI also enables accurate delineation of tumors from surrounding post-obstructive atelectatic areas, which is important for therapy planning. In some cases, it can be difficult to distinguish between lesions and regions of post-obstructive atelectasis or pneumonitis, because these secondary changes and the tumor tend to be enhanced to a similar degree on CE-CT. On T2-weighted or CE-T1-weighted images, however, post-obstructive atelectasis and pneumonitis often have a signal intensity distinct from that of tumors $[100,101]$, possibly due pulmonary vasculature invasion. Furthermore, researchers have reported that post-obstructive atelectasis $A D C$ value appears to be higher than those of lung tumors (Fig. 4) $[102,103]$.

Recent studies have focused on the potential of MRI-based imaging biomarkers that can stratify the risk in lung cancer patients. As DWI can provide information about tumor cellularity, investigators have attempted to differentiate lung cancer subtypes using ADC values. Differences in ADC values have been reported for small cell lung cancer and NSCLC $[104,105]-A D C$ values in the former were lower, probably

Table 4. Diagnostic performance of diffusion-weighted MRI in terms of distinguishing between malignant and benign pulmonary nodules

\begin{tabular}{|c|c|c|c|c|c|c|c|c|}
\hline Study & Modality & $\begin{array}{c}\text { Field of } \\
\text { strength }(T)\end{array}$ & $\begin{array}{c}\text { MR } \\
\text { sequence }\end{array}$ & Parameters & $\begin{array}{c}\text { No. of } \\
\text { nodules }\end{array}$ & $\begin{array}{c}\text { Sensitivity } \\
(\%)\end{array}$ & $\begin{array}{l}\text { Specificity } \\
(\%)\end{array}$ & $\begin{array}{c}\text { Accuracy } \\
(\%)\end{array}$ \\
\hline \multirow[t]{2}{*}{$\begin{array}{l}\text { Coolen et al. } \\
\text { (2014) [92] }\end{array}$} & \multirow[t]{2}{*}{$\begin{array}{l}\text { DWI } \\
\text { Dynamic } \\
\text { contrast- } \\
\text { enhanced MR }\end{array}$} & \multirow[t]{2}{*}{3.0} & \multirow[t]{2}{*}{$\begin{array}{l}\text { Spin echo-planar } \\
\text { 3D T1-weighted fast } \\
\text { field echo }\end{array}$} & $\begin{array}{l}\mathrm{ADC}_{\text {high }}(\mathrm{ADC} \\
\text { determined using } \\
\text { b-values } 500,750, \\
\text { and } 1,000 \mathrm{sec} / \mathrm{mm}^{2} \text { ) }\end{array}$ & \multirow[t]{2}{*}{54} & 98 & 82 & 94 \\
\hline & & & & Visual curve typing & & 100 & 55 & 91 \\
\hline \multirow[t]{2}{*}{$\begin{array}{c}\text { Koyama et al. } \\
\text { (2015) [42] }\end{array}$} & \multirow[t]{2}{*}{ DWI } & \multirow[t]{2}{*}{1.5} & \multirow{2}{*}{$\begin{array}{l}\text { Half-Fourier } \\
\text { single-shot short } \\
\text { inversion time } \\
\text { inversion recovery } \\
\text { turbo spin echo } \\
\text { echo-planar imaging }\end{array}$} & $\begin{array}{l}\text { Signal intensity ratios } \\
\text { between lesion and } \\
\text { spinal cord at b-value } \\
500 \mathrm{sec} / \mathrm{mm}^{2}\end{array}$ & \multirow[t]{2}{*}{36} & NA & 89 & 78 \\
\hline & & & & $\begin{array}{l}\text { Signal intensity ratios } \\
\text { between lesion and } \\
\text { spinal cord at b-value } \\
1,000 \mathrm{sec} / \mathrm{mm}^{2}\end{array}$ & & NA & 89 & 72 \\
\hline \multirow{2}{*}{$\begin{array}{l}\text { Mori et al. } \\
\text { (2008) [88] }\end{array}$} & DWI & 1.5 & SE, echo-planar & Minimum ADC & \multirow[t]{2}{*}{140} & 70 & 97 & NA \\
\hline & $\mathrm{PET} / \mathrm{CT}$ & NA & NA & $\begin{array}{l}\text { Contrast ratio of stan- } \\
\text { dard uptake value }\end{array}$ & & 72 & 79 & NA \\
\hline \multirow{3}{*}{$\begin{array}{l}\text { Ohba et al. } \\
\qquad(2011) \text { [91] }\end{array}$} & DWI & 1.5 & SE, echo-planar & Minimum ADC & \multirow[t]{3}{*}{76} & 91 & 90 & NA \\
\hline & & 3.0 & & & & 88 & 94 & NA \\
\hline & $\mathrm{PET} / \mathrm{CT}$ & NA & NA & $\mathrm{SUV}_{\max }$ & & 94 & 94 & NA \\
\hline $\begin{array}{l}\text { Satoh et al. } \\
\text { (2008) [89] }\end{array}$ & DWI & 1.5 & Echo-planar & $\begin{array}{l}\text { 5-Point rank scale of } \\
\text { signal intensity on } \\
\text { DWI at b-value } \\
1,000 \mathrm{sec} / \mathrm{mm}^{2}\end{array}$ & 54 & 89 & 61 & 80 \\
\hline \multirow[t]{2}{*}{$\begin{array}{l}\text { Usuda et al. } \\
\text { (2014) [93] }\end{array}$} & DWI & 1.5 & $\begin{array}{l}\text { Single-shot echo- } \\
\text { planar }\end{array}$ & Mean ADC & 143 & 80 & 66 & 78 \\
\hline & $\mathrm{PET} / \mathrm{CT}$ & NA & & $\mathrm{SUV}_{\max }$ & & 70 & 66 & 69 \\
\hline \multirow[t]{2}{*}{$\begin{array}{l}\text { Uto et al. } \\
\qquad(2009) \text { [90] }\end{array}$} & \multirow[t]{2}{*}{ DWI } & \multirow[t]{2}{*}{1.5} & Spin echo-planar & $\begin{array}{l}\text { Signal intensity ratios } \\
\text { between lesion and } \\
\text { spinal cord at b-value } \\
1,000 \mathrm{sec} / \mathrm{mm}^{2}\end{array}$ & \multirow[t]{2}{*}{28} & NA & NA & 86 \\
\hline & & & & $A D C$ & & NA & NA & 50 \\
\hline
\end{tabular}

MRI, magnetic resonance imaging; MR, magnetic resonance; DWI, diffusion-weighted imaging; ADC, apparent diffusion coefficient; NA, not applicable; $\mathrm{PET} / \mathrm{CT}$, positron emission tomography/computed tomography; SE, spin echo; $\mathrm{SUV}_{\max }$, maximum standardized uptake value. 

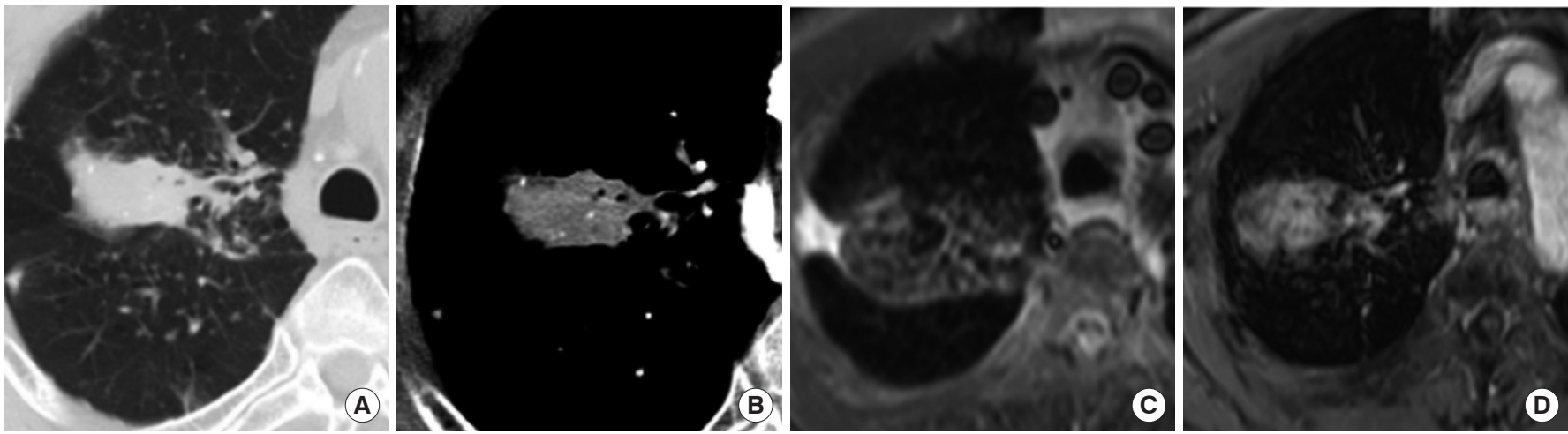

Fig. 3. Case of an 81-year-old man with progressive massive fibrosis (PMF) confirmed based on percutaneous biopsy. (A) Thin-section computed tomography (CT) image showing a well-defined mass in the right upper lobe. Multiple small nodules indicative of pneumoconiosis are also seen in the surrounding lung tissue. (B) The mass has an inhomogeneous enhancement pattern on contrast-enhanced CT. Differentiating PMF from lung cancer on the basis of CT findings was difficult. (C, D) The main nodule showed very low signal intensity on T2-weighted magnetic resonance imaging (MRI) (C) and a heterogeneous enhancement pattern on contrast-enhanced T1-weighted MRI (D), which indicated that PMF was more likely than lung cancer.
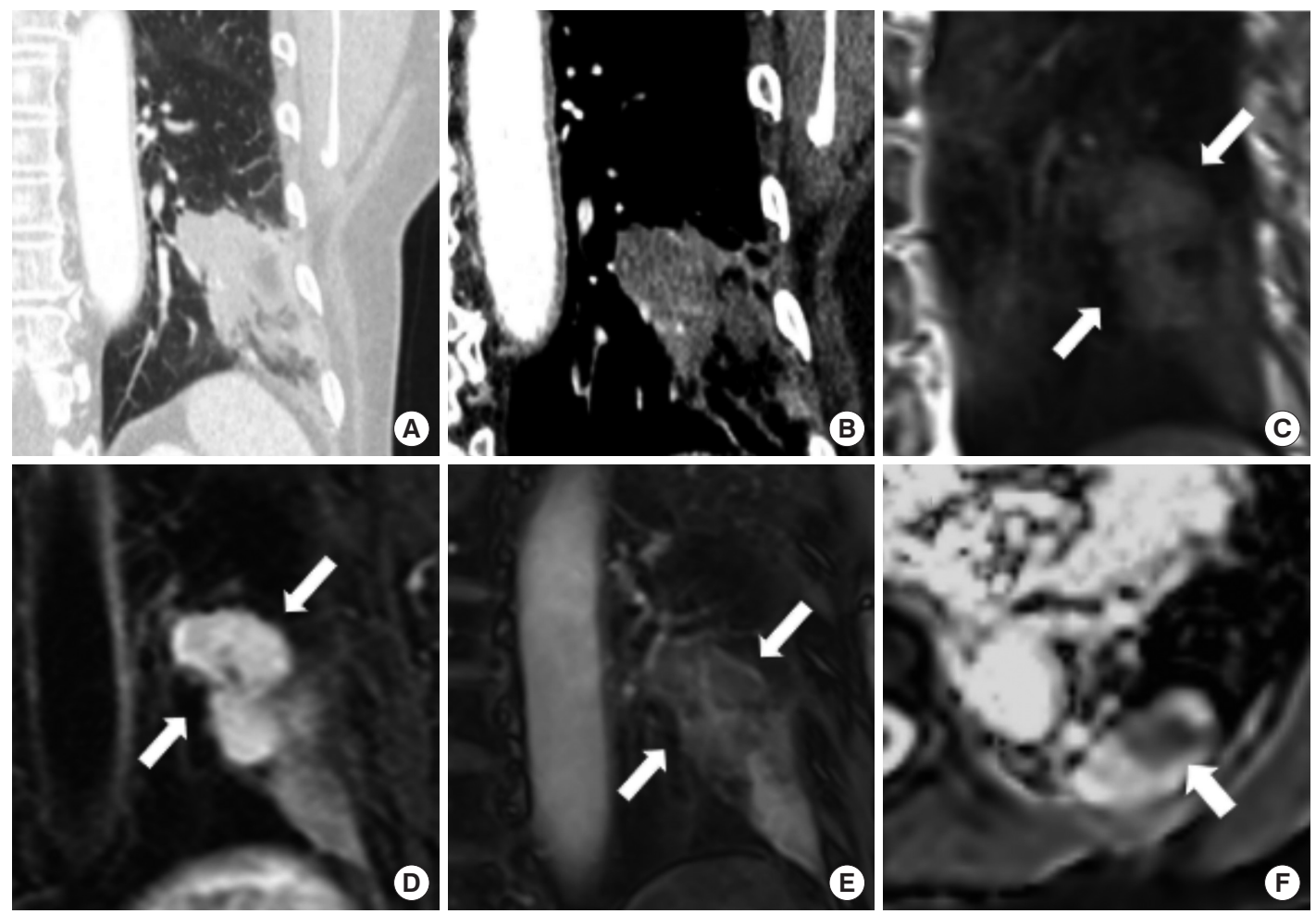

Fig. 4. Case of a 70-year-old female with adenocarcinoma. (A) Thin-section computed tomography (CT) shows a tumor with distal atelectasis in the left lower lobe. (B) Contrast-enhanced thin-section CT shows homogenous enhancement in the tumor and the atelectatic region, but the extent of the tumor cannot be accurately determined. (C) Black-blood T1-weighted magnetic resonance imaging shows the tumor (arrows) and distal atelectasis as regions of intermediate and low signal intensity, respectively. (D) T2-weighted images show the tumor (arrows) and atelectasis as regions of high and intermediate signal intensity, respectively. (E) A post-contrast T1-weighted image clearly showing the extent of the tumor (arrows) and secondary atelectasis. (F) In the apparent diffusion coefficient (ADC) map, the mean ADC value of the tumor $\left(1.341 \times 10^{-3} \mathrm{~mm}^{2} / \mathrm{sec}\right)$ (arrow) was lower than that of the surrounding atelectatic region $\left(2.947 \times 10^{-3} \mathrm{~mm} / \mathrm{sec}\right)$.

due to histologic factors such as high cellularity tumors with large nuclei and almost no cytoplasm, which reduce diffusion-based motion [106]. Among the NSCLCs, adenocarcino- ma $A D C$ value was significantly higher than that of squamous cell carcinoma (Figs. 5, 6) [105]. Mucinous adenocarcinomas, which have characteristic mucin production, in particular 

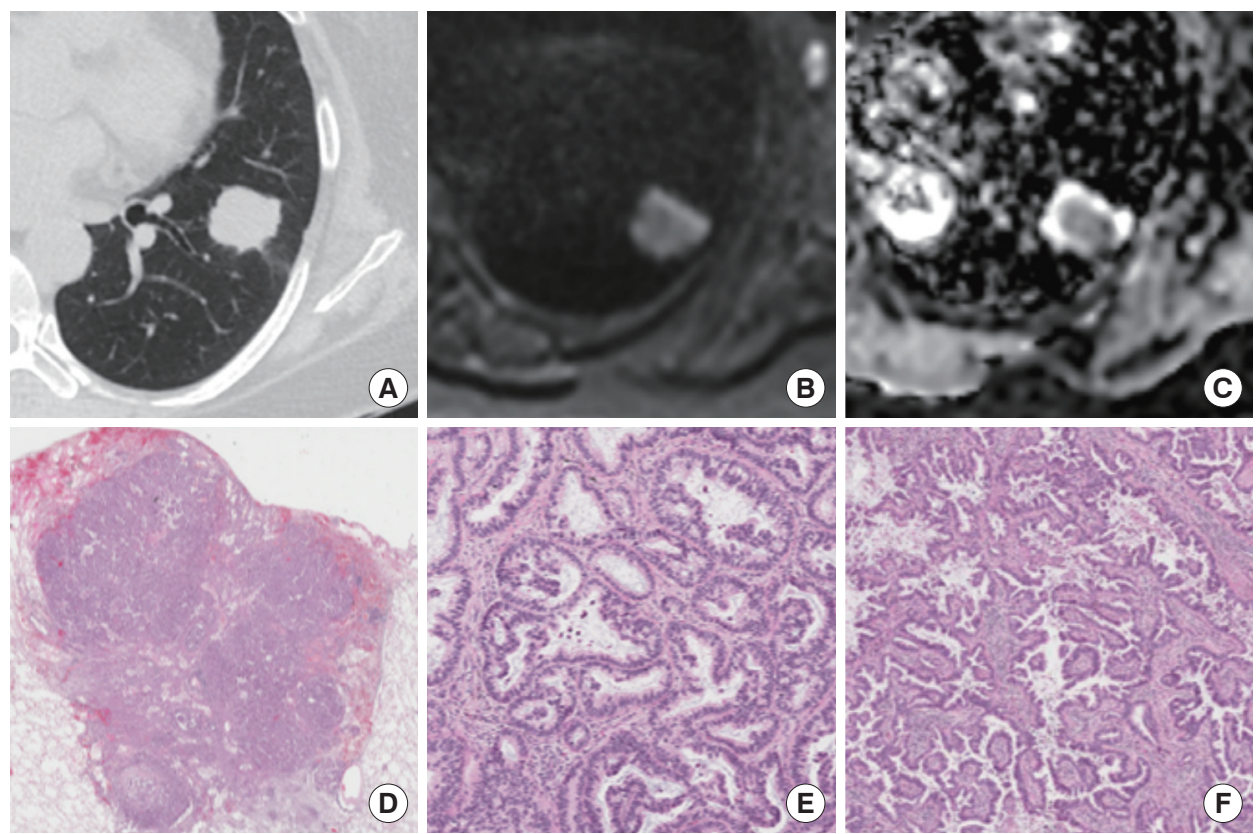

Fig. 5. Case of 63-year-old female with adenocarcinoma in the left lower lobe. (A) Conventional computed tomography shows a lobulated nodule in the left lower lobe. (B) Diffusion-weighted imaging $(b$-value $=700$ ) shows a high signal. (C) The mean apparent diffusion coefficient of the carcinoma was $1.300 \times 10^{-3} \mathrm{~mm}^{2} / \mathrm{sec}$. (D) Photomicrograph of hematoxylin and eosin (H\&E) staining $(\times 10)$ shows invasive adenocarcinoma, with high magnification $(\times 100)$ images showing the acinar pattern $(E)$ and papillary pattern $(F)$.
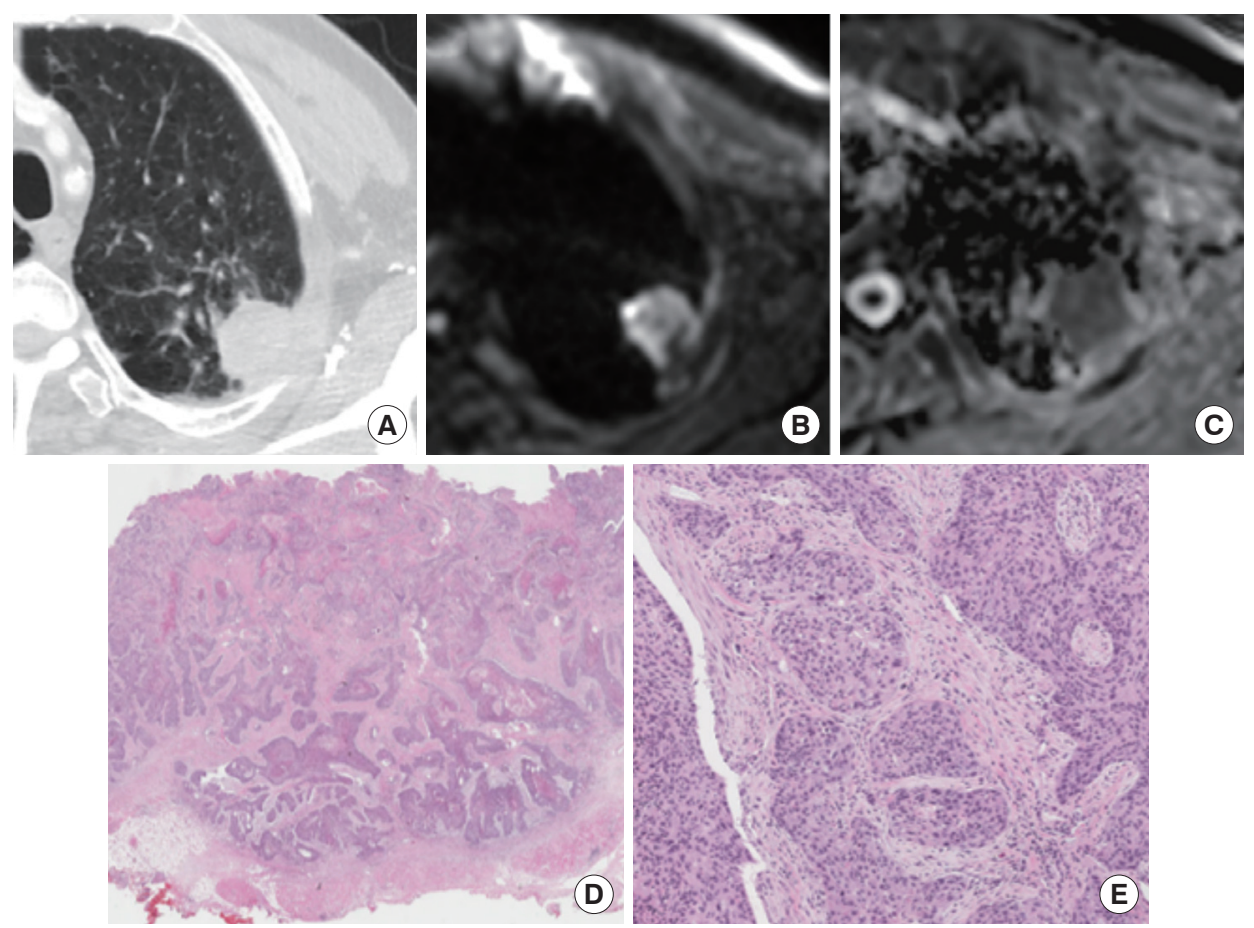

Fig. 6. Case of a 74-year-old male with squamous cell carcinoma in the left upper lobe. (A) Conventional computed tomography shows a welldefined nodule in the left upper lobe. (B) Diffusion-weighted imaging ( $b$-value $=700)$ shows a high signal. (C) The mean apparent diffusion coefficient of the carcinoma was $0.979 \times 10^{-3} \mathrm{~mm}^{2} / \mathrm{sec}$. (D) Photomicrograph of hematoxylin and eosin (H\&E) staining $(\times 10)$ shows squamous cell carcinoma, $(E)$ with high magnification $(H \& E, \times 100)$ showing that the moderately differentiated squamous nodule contains nests of polygonal cells. 


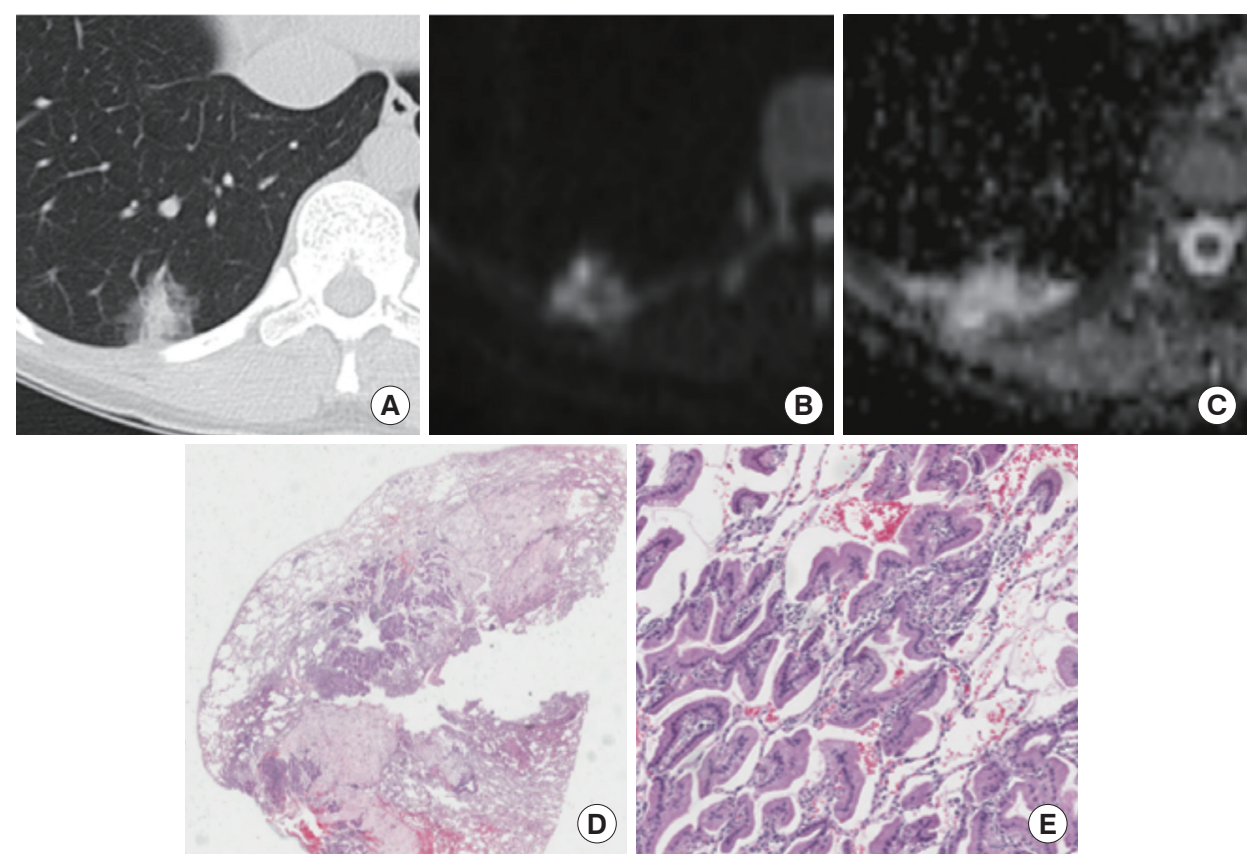

Fig. 7. Case of a 40-year-old female with mucinous adenocarcinoma in the right lower lobe. (A) Conventional computed tomography shows a part-solid nodule in the right lower lobe. (B) Diffusion-weighted imaging (b-value $=500)$ shows a high signal. (C) The mean apparent diffusion coefficient of the carcinoma was $3.453 \times 10^{-3} \mathrm{~mm}^{2} / \mathrm{sec}$. (D) Photomicrograph of hematoxylin and eosin (H\&E) staining ( $\left.\times 10\right)$ shows invasive mucinous adenocarcinoma, $(E)$ with high magnification $(\times 100)$ showing the cuboidal tumor cells with abundant cytoplasmic mucin.

tend to have significantly higher ADC values than other types (Fig. 7) [93,105]. Lee et al. [107] showed that mean ADC values correlate well with lung adenocarcinoma histologic grades, and Kanauchi et al. [108] reported that DWI might be useful for predicting the invasiveness of stage IA NSCLC.

As for CEST imaging, APT-weighted imaging appears to be as useful as DWI and FDG-PET/CT for differentiating between malignant and benign nodules [35]. Although ADC sensitivity was significantly higher than that of magnetization transfer ratio asymmetry (3.5 ppm) and maximum standardized uptake value $\left(\mathrm{SUV}_{\text {max }}\right)$, its specificity was significantly lower $(\mathrm{P}<$ 0.05) [35].

\section{Lung cancer staging}

Accurate staging based on primary tumor and regional lymph node features and the presence of metastasis is an important step in determining appropriate management and predicting lung cancer prognosis [109,110].

\section{$T$ descriptor}

Although CT has been used as the standard reference for lung cancer T-staging, it has limited value in evaluating tumor invasion into adjacent structures because of relatively low soft tissue contrast, which can cause underestimation of the Tstage in advanced lung cancer [111]. On the other hand, MRI was earlier proposed to be superior to CT for T-staging evaluations because of its excellent soft tissue contrast and high spatial resolution (Fig. 8) [111-113].

ECG-triggered MR angiography improves image quality by reducing cardiac motion- and breathing-related artifacts in pulmonary vessels and allowing the detection of hilar and mediastinal invasion in lung cancer (sensitivity, $89 \%$ to $90 \%$; specificity, $83 \%$ to $87 \%$; accuracy, $86 \%$ to $88 \%$ ) [113]. Zhang et al. [114] reported that 3T CE-MRI using free-breathing, fat-saturated, radial VIBE was superior to $\mathrm{CT}$ in detecting and distinguishing NSCLC without visceral pleural surface invasion (VPSI) from that with VPSI (sensitivity, specificity, and accuracy: $83 \%, 95 \%$, and $91 \%$, respectively). Moreover, MRI is superior to $\mathrm{CT}$ in evaluating brachial plexus invasion of superior sulcus tumors and is used as the reference standard (Fig. 9) [115]. One study showed that CE-T1-weighted fat-suppression and T2-weighted fat-suppression were the most sensitive sequences for evaluating vertebral invasion of superior sulcus tumors [116]; therefore, MRI is useful for pre-operative T-staging in advanced lung cancer, offering excellent soft tissue contrast. Another study showed that MRI was slightly superior to multi-detector CT in advanced-stage NSCLC T-staging, whereas multi-detector CT was more accurate for early-stage tumors [111]. Table 5 shows the reported diagnostic performance of MRI for lung cancer T-staging. 

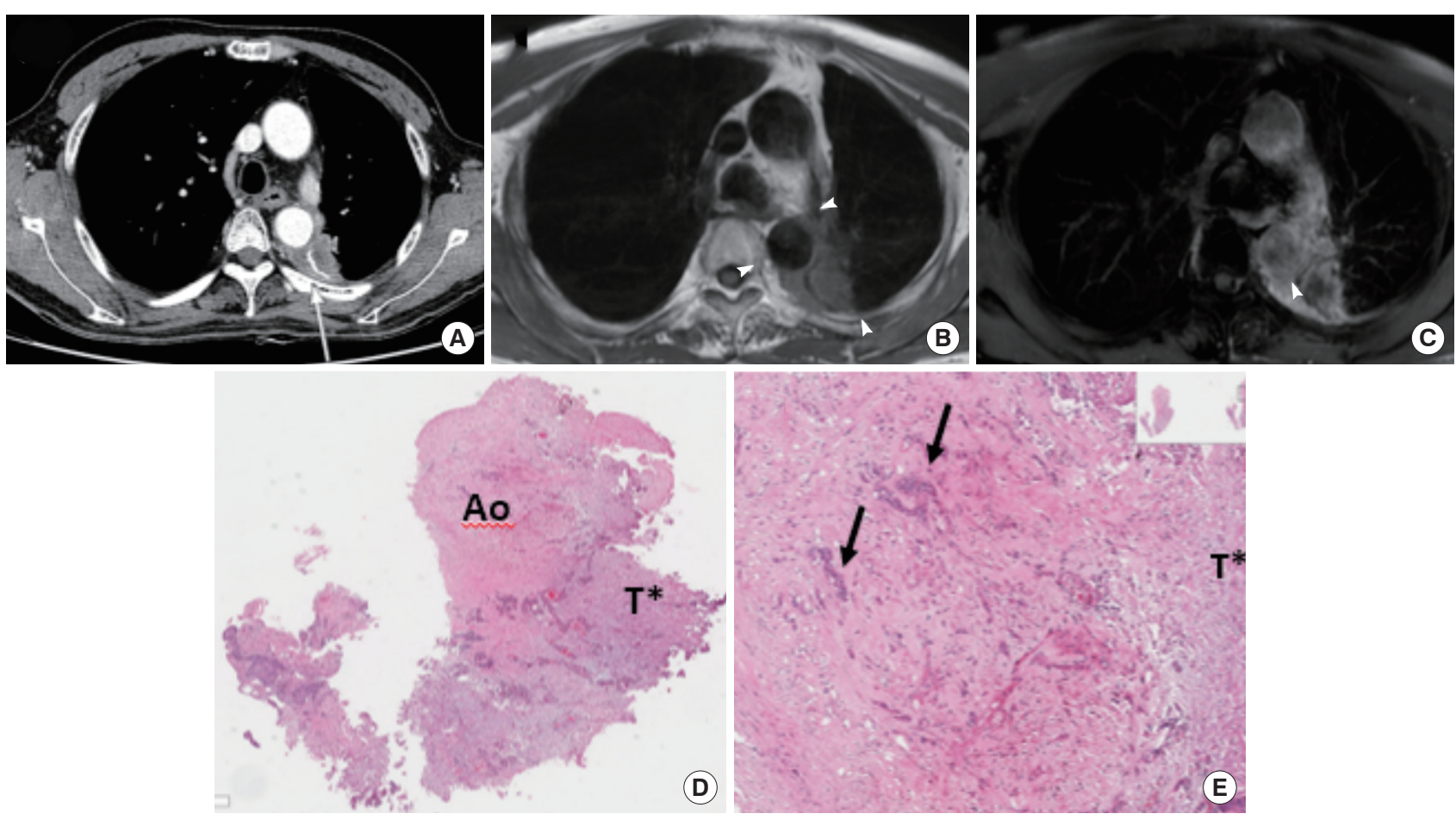

Fig. 8. Case of a 63-year-old woman with squamous cell carcinoma in the left upper lobe who underwent a post-salvage left upper lobectomy and en bloc superior segmentectomy of the left lower lobe. (A) Contrast-enhanced computed tomography images showing a $35 \mathrm{~mm}$ mass around the suture materials in the left lower lobe abutting the descending thoracic aorta (arrow). (B) T1-weighted magnetic resonance imaging (MRI) revealed an isodense mass in the left lower lobe encasing 180-degrees of the descending aorta (arrows). (C) Post-contrast T1weighted MRI with fat-suppression revealed a heterogeneously enhanced tumor with suspicious invasion of the descending thoracic aorta (arrowhead). (D, E) Microscopic evaluation of the resection specimen obtained after left pneumonectomy stained with hematoxylin and eosin showed the tumor $\left(\mathrm{T}^{\star}\right)$ encasing the aorta (Ao) and (arrows) in the aorta wall (original magnification: $\mathrm{D}, 40 \times ; \mathrm{E}, 400 \times$ ).
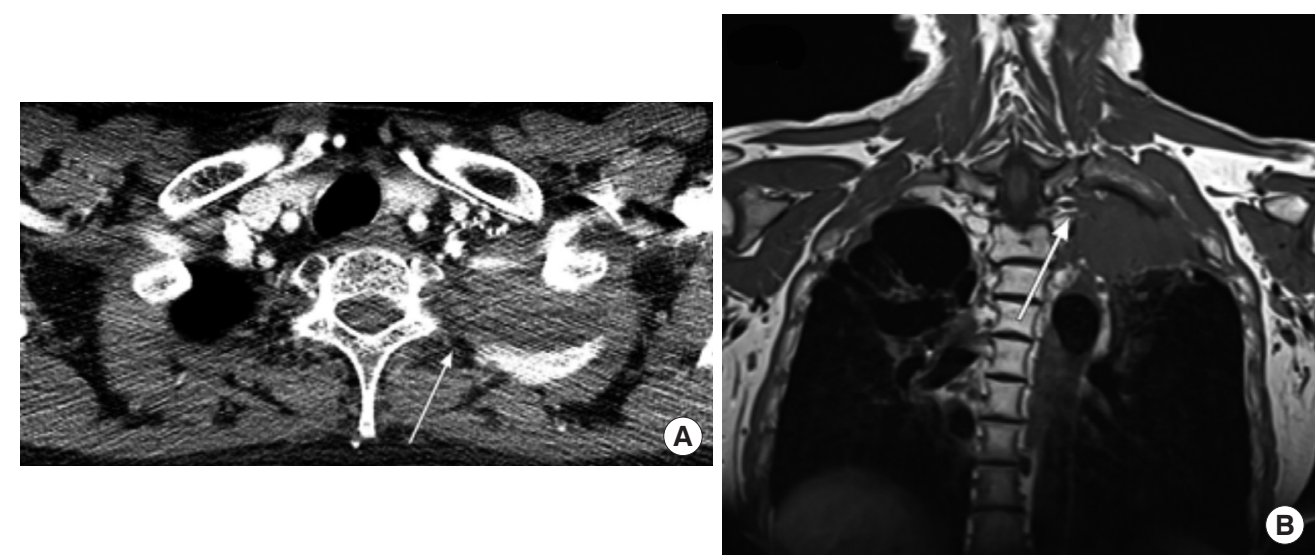

Fig. 9. A superior sulcus tumor in a 48-year-old man with left shoulder pain. (A) Axial computed tomography image shows a superior sulcus tumor in the left lung apex. The mass abuts the T1 vertebral body (arrow), but the presence or degree of any extension into the foramen is difficult to determine. (B) Coronal T1-weighted magnetic resonance imaging revealed that the left superior sulcus invaded the distal brachial plexus of the T1 nerve (arrow). As invasion of the brachial plexus indicates tumor unresectability, the patient underwent concurrent chemoradiation therapy.

\section{N descriptor}

Accurate $\mathrm{N}$-staging is of utmost importance when choosing an appropriate treatment strategy. Differentiating between metastatic and non-metastatic lymph nodes depends on the size and shape criteria used with MRI and CT. A meta-analysis demonstrated the high diagnostic performance of MRI for 
PRECISION AND FUTURE MIEDICINE

MRI for lung cancer

Table 5. Diagnostic performance of MRI in terms of T-factor evaluation

\begin{tabular}{|c|c|c|c|c|c|c|c|c|c|c|c|}
\hline \multirow{2}{*}{ Study } & \multirow{2}{*}{$\begin{array}{c}\text { Field } \\
\text { strength }(T)\end{array}$} & \multirow{2}{*}{ Method } & \multicolumn{3}{|c|}{ MRI } & \multicolumn{3}{|c|}{$\mathrm{CT}$} & \multicolumn{3}{|c|}{$\mathrm{PET} / \mathrm{CT}$} \\
\hline & & & Se $(\%)$ & $\mathrm{Sp}(\%)$ & Ac $(\%)$ & $\mathrm{Se}(\%)$ & $\mathrm{Sp}(\%)$ & Ac (\%) & Se $(\%)$ & $\mathrm{Sp}(\%)$ & $A c(\%)$ \\
\hline $\begin{array}{l}\text { Webb et al. } \\
\text { (1991) [34] }\end{array}$ & 0.35 or 1.5 & $\begin{array}{l}\text { ECG-gated T1- and T2- } \\
\text { weighted spine-echo }\end{array}$ & 80 & 56 & 73 & 84 & 63 & 78 & NA & NA & NA \\
\hline $\begin{array}{l}\text { Sakai et al. } \\
\text { (1997) [112] }\end{array}$ & 1.5 & Free-breathing cine-GRASS & 10 & 70 & 76 & 80 & 65 & 68 & NA & NA & NA \\
\hline $\begin{array}{l}\text { Ohno et al. } \\
\text { (2001) [113] }\end{array}$ & 1.5 & $\begin{array}{l}\text { Dynamic ECG-triggered } \\
\text { 3D-GRE }\end{array}$ & $78-90$ & $73-87$ & $75-88$ & $67-70$ & $60-64$ & $68-71$ & NA & NA & NA \\
\hline $\begin{array}{l}\text { Tang et al. } \\
\text { (2015) [111] }\end{array}$ & 3 & $\begin{array}{l}\text { Breath-hold dynamic CE } \\
\text { 2D-GRE }\end{array}$ & NA & NA & 82.2 & NA & NA & 84.4 & NA & NA & NA \\
\hline
\end{tabular}

MRI, magnetic resonance imaging; CT, computed tomography; PET, positron emission tomography; Se, sensitivity; Sp, specificity; Ac, accuracy; ECG, electrocardiogram; NA, not applicable; GRASS, gradient-recalled acquisition in steady state; GRE, gradient echo; CE, contrast-enhanced.

Table 6. Diagnostic performance of MRI in terms of N-factor evaluation

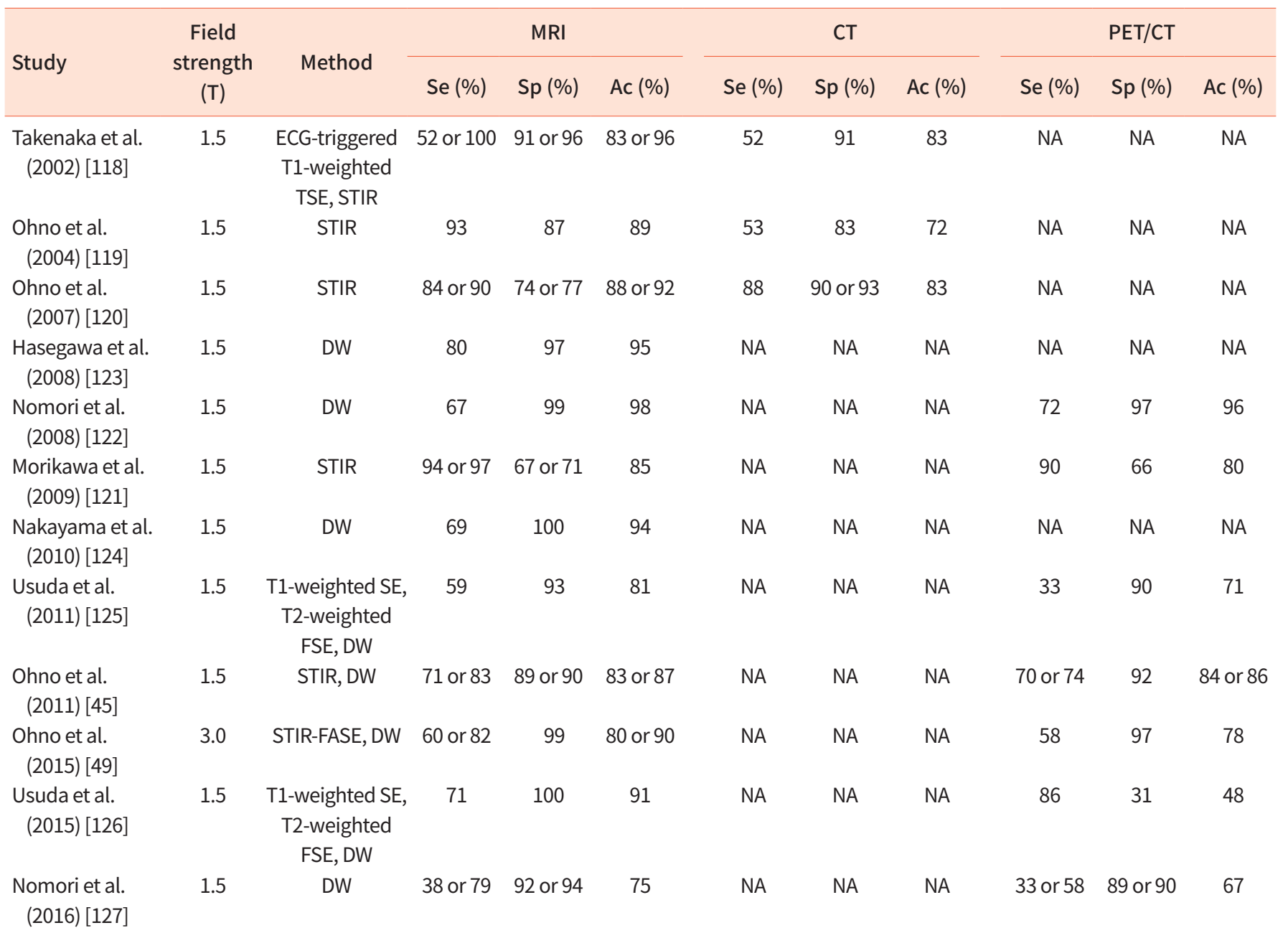

MRI, magnetic resonance imaging; CT, computed tomography; PET, positron emission tomography; Se, sensitivity; Sp, specificity; Ac, accuracy; ECG, electrocardiogram; TSE, turbo spin echo; STIR, short inversion time inversion recovery; NA, not applicable; DW, diffusion-weighted; SE, spin echo; FSE, fast spin echo; FASE, fast advanced spin echo.

$\mathrm{N}$-staging in NSCLC on both a per-patient and per-node basis, supporting the clinical relevance of MRI for $\mathrm{N}$-staging in
NSCLC $[11,117]$. Table $6[45,49,118-127]$ shows the diagnostic performance of thoracic MRI for lung cancer $\mathrm{N}$-staging. STIR 

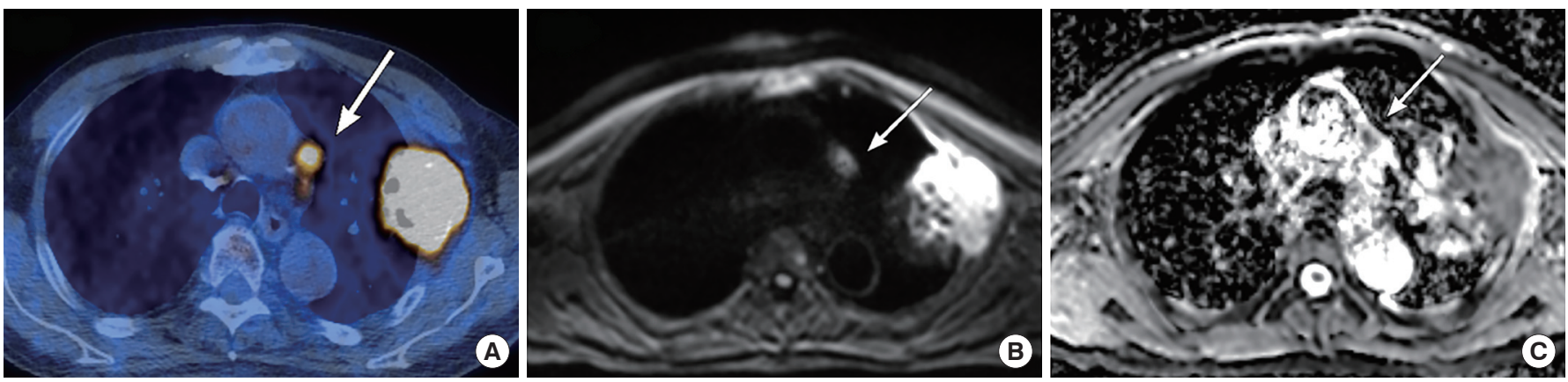

Fig. 10. Case of an 80-year-old man with adenocarcinoma in the left upper lobe. (A) Fused positron emission tomography/computed tomography image clearly showing a malignant subaortic node (arrow). (B) The lymph node depicted in the b=700 diffusion-weighted image (arrow) (C) had low apparent diffusion coefficient (ADC) values in the corresponding, mono-exponential ADC map (arrow). The subaortic node was confirmed as being metastatic based on an endobronchial ultrasound bronchoscopy-guided transbronchial needle biopsy.

TSE imaging and DWI are also useful for determining the N descriptor in NSCLC [13]. STIR TSE images enhance the net tissue contrast for malignant lymph nodes compared with benign lymph nodes as $\mathrm{T} 1$ and $\mathrm{T} 2$ relaxation times increase [45]. STIR TSE imaging can also be useful for N-staging in NSCLC, with equal or higher sensitivity ( $83.7 \%$ to $100 \%)$, specificity $(70.9 \%$ to $93.1 \%)$, and accuracy ( $84.7 \%$ to $92.2 \%)$ than CT, FDG-PET, and PET/CT [118-121]. DWI is another promising MR technique for distinguishing between metastatic and non-metastatic lymph nodes (Fig. 10) [122] (sensitivity, specificity, and accuracy: $83.7 \%-100 \%, 74.4 \%-96 \%$, and $79.5 \%-$ $95 \%$, respectively) equal to or higher than those for FDG-PET and PET/CT [49,122,123,128,129]. Two meta-analyses reported that the sensitivity and specificity of DWI were 0.72 and $0.95-0.97$ and those of FDG-PET/CT were $0.65-0.75$ and 0.89 0.93 , respectively $[130,131]$.

\section{M descriptor}

In routine clinical practice, distant metastasis is evaluated using CE-CT, bone scintigraphy, brain MRI, and PET/CT. Wholebody MRI has become clinically feasible and provides acceptable accuracy for NSCLC M-staging compared to PET/CT [6]; it is more useful for evaluating brain and hepatic metastases, whereas PET/CT is useful for detecting lymph node and soft tissue metastases [132]. As MRI provides better contrast than PET/CT, metastases in the brain, liver, and kidney can easily be detected, whereas with PET/CT, metastases can be obscured by physiological uptake [132], which also necessitates additional brain MRI for complete M-staging. Recently, fibroblast activating protein inhibitor (FAPI) tracers that have low uptake in almost all normal tissues, including the brain and bowel, have been developed [133,134]. However, despite the low uptake in the brain on FAPI-PET/CT being a potential ad- vantage over FDG for M-staging [134], false-positives are frequent in bone and liver MRI, because hemangiomas, nodular hyperplasia flow-related enhancement, and marrow signal intensity changes can mimic metastases [132]. Yi et al. [135] used co-registered whole-body MR-PET as a staging tool and found that NSCLC was correctly up-staged in $25.9 \%$ and $21.7 \%$ of patients in the MR-PET and PET/CT plus brain MRI groups, respectively (4.2\% difference, $95 \%$ confidence interval $[\mathrm{Cl}],-6.1$ to $14.5 ; \mathrm{P}=0.426$ ). Hybrid PET/MR systems have also recently become clinically feasible. The diagnostic accuracy of $\mathrm{PET} / \mathrm{MR}$ for $\mathrm{M}$ descriptor assessment was equal to or higher than that of PET/CT $[136,137]$. Table 7 shows the reported diagnostic performances of whole-body MRI and PET/ MRI for M-staging in lung cancer [43,46,56,58,132,136-138]. The advantages and disadvantages of PET/CT and chest MRI for lung cancer staging are summarized in Table 8.

\section{Prediction of post-operative pulmonary function}

Approximately $90 \%$ of lung cancer patients have underlying chronic obstructive pulmonary disease (COPD) or cardiovascular disorders, which are associated with a high-risk of intraoperative and post-operative complications [139]. As COPD patients show regional differences in pulmonary function because of lung tissue destruction, it is important to assess these in pre-operative evaluation for lung resections in such patients [140]. Spirometry, CT, and nuclear medicinebased examinations are standard pre-operative evaluations for patients undergoing lung resection [141]. Recently, various MRI techniques have been used to predict post-operative lung function. 3D DCE-perfusion MRI is a useful new technique for evaluating regional pulmonary perfusion and assessing a patient's physiological and pathological conditions [142], showing superiority to qualitatively assessed pulmo- 
PRECISION AND FUTURE MEDICINE

MRI for lung cancer

Table 7. Diagnostic performance of MRI in terms of M-factor evaluation

\begin{tabular}{|c|c|c|c|c|c|c|c|c|c|c|}
\hline \multirow{2}{*}{ Study } & \multirow{2}{*}{$\begin{array}{c}\text { Field } \\
\text { strength }(T)\end{array}$} & \multicolumn{3}{|c|}{ Whole-body MR } & \multicolumn{3}{|c|}{ FDG-PET MR } & \multicolumn{3}{|c|}{$\mathrm{PET} / \mathrm{CT}$} \\
\hline & & Se $(\%)$ & Sp (\%) & Ac (\%) & Se $(\%)$ & $\mathrm{Sp}(\%)$ & Ac (\%) & Se $(\%)$ & $\mathrm{Sp}(\%)$ & Ac $(\%)$ \\
\hline Ohno et al. (2007) [138] & 1.5 & NA & NA & 80 & NA & NA & NA & NA & NA & 73.3 \\
\hline Yi et al. (2008) [132] & 3.0 & NA & NA & 86 & NA & NA & NA & NA & NA & 86 \\
\hline Ohno et al. (2008) [43] & 1.5 & 58 or 70 & 88 or 92 & 82 or 88 & NA & NA & NA & 63 & 65 & 88 \\
\hline Takenaka et al. (2009) [46] & 1.5 & 73 or 96 & 94 or 96 & 94 or 96 & NA & NA & NA & 97 & 96 & 96 \\
\hline Ohno et al. (2015) [56] & 3.0 & 100 & 88 & 99 & 93 or 100 & 81 or 88 & 91 or 99 & 93 & 75 & 91 \\
\hline Huellner et al. (2016) [136] & 3.0 & NA & NA & NA & NA & NA & 81 & NA & NA & 83 \\
\hline Lee et al. (2016) [137] & 3.0 & NA & NA & NA & 83 & 100 & 98 & 67 & 100 & 96 \\
\hline Ohno et al. (2020) [58] & 1.5 or 3.0 & NA & NA & 94 or 97 & NA & NA & 94 or 97 & NA & NA & 96 \\
\hline
\end{tabular}

MRI, magnetic resonance imaging; MR, magnetic resonance; FDG, fluorodeoxyglucose; PET, positron emission tomography; CT, computed tomography; Se, sensitivity; Sp, specificity; Ac, accuracy; NA, not applicable.

Table 8. Advantages and disadvantages of MRI and PET/CT for lung cancer staging

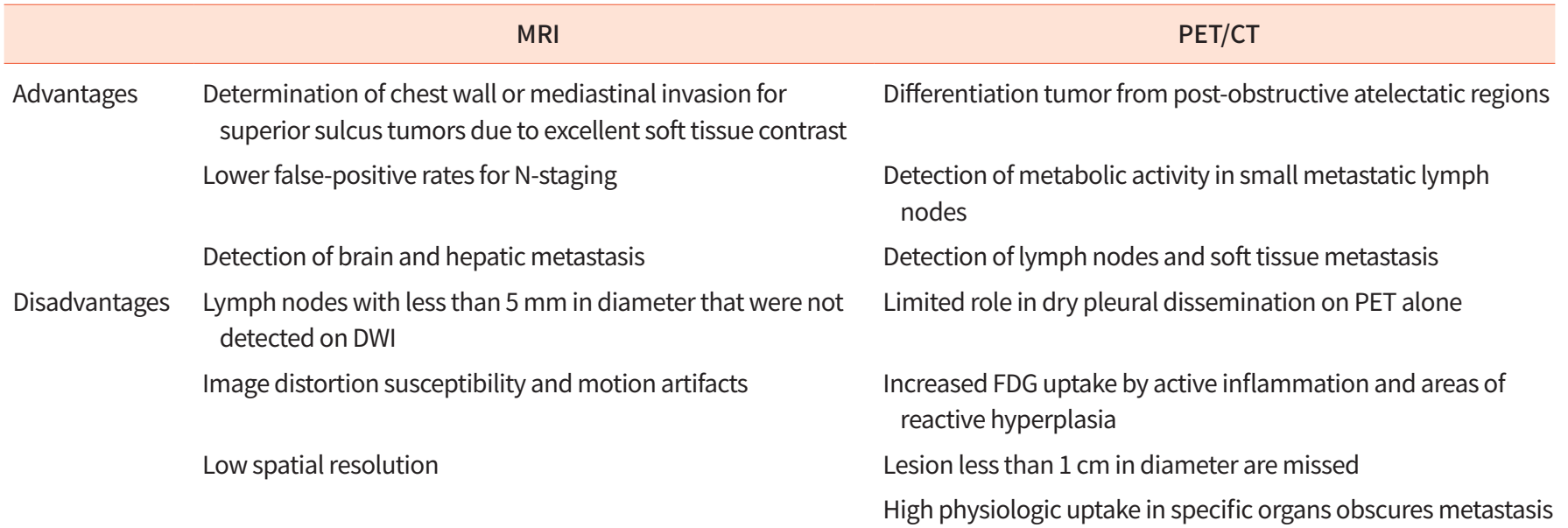

MRI, magnetic resonance imaging; DWI, diffusion-weighted imaging; PET, positron emission tomography; CT, computed tomography; FDG, fluorodeoxyglucose.

nary perfusion scintigraphy, $\mathrm{CT}$, and single-photon emission CT $[141,142]$. The correlation between actual post-operative forced expiratory volume in 1 second $\left(\mathrm{FEV}_{1}\right)$ and post-operative $\mathrm{FEV}_{1}$ predicted using 3D DCE-perfusion MRI is excellent $[141,142]$. One study reported that the post-operative $\mathrm{FEV}_{1}$ predicted using non-CE perfusion MRI with the fresh blood technique correlated significantly with actual post-operative $\mathrm{FEV}_{1}(r=0.98)$ [143]. Non-CE perfusion MRI is a technique for evaluating post-operative lung function in patients with contraindications for gadolinium contrast agent use [13]. Oxygen-enhanced MRI is another potential approach for imaging pulmonary ventilation [144]. A study showed an excellent correlation between the $\mathrm{FEV}_{1}$ predicted using oxygen-enhanced MR and actual post-operative $\mathrm{FEV}_{1}\left(r^{2}=0.81\right)[145]$.

\section{Post-operative lymphatic leakage evaluation}

The use of aggressive surgical techniques for improving the curability of patients with cancer may contribute to increased post-operative lymphatic leakage. Several studies have reported that post-operative chylothorax often occurs after pneumonectomy $(0.37 \%)$ and lobectomy $(0.26 \%-2.3 \%)$ [146-148]. For patients with persistent high-output chylothorax for whom conservative dietary treatment has failed, re-operation to ligate the thoracic duct is necessary $[149,150]$.

The most popular traditional imaging modality for lymphatics is scintigraphy, but it has poor spatial resolution [151,152]. Direct lymphangiography requires cannulation of peripheral lymphatic channels and infusion of an oil-based contrast agent. Catheterization of small lymphatic channels 

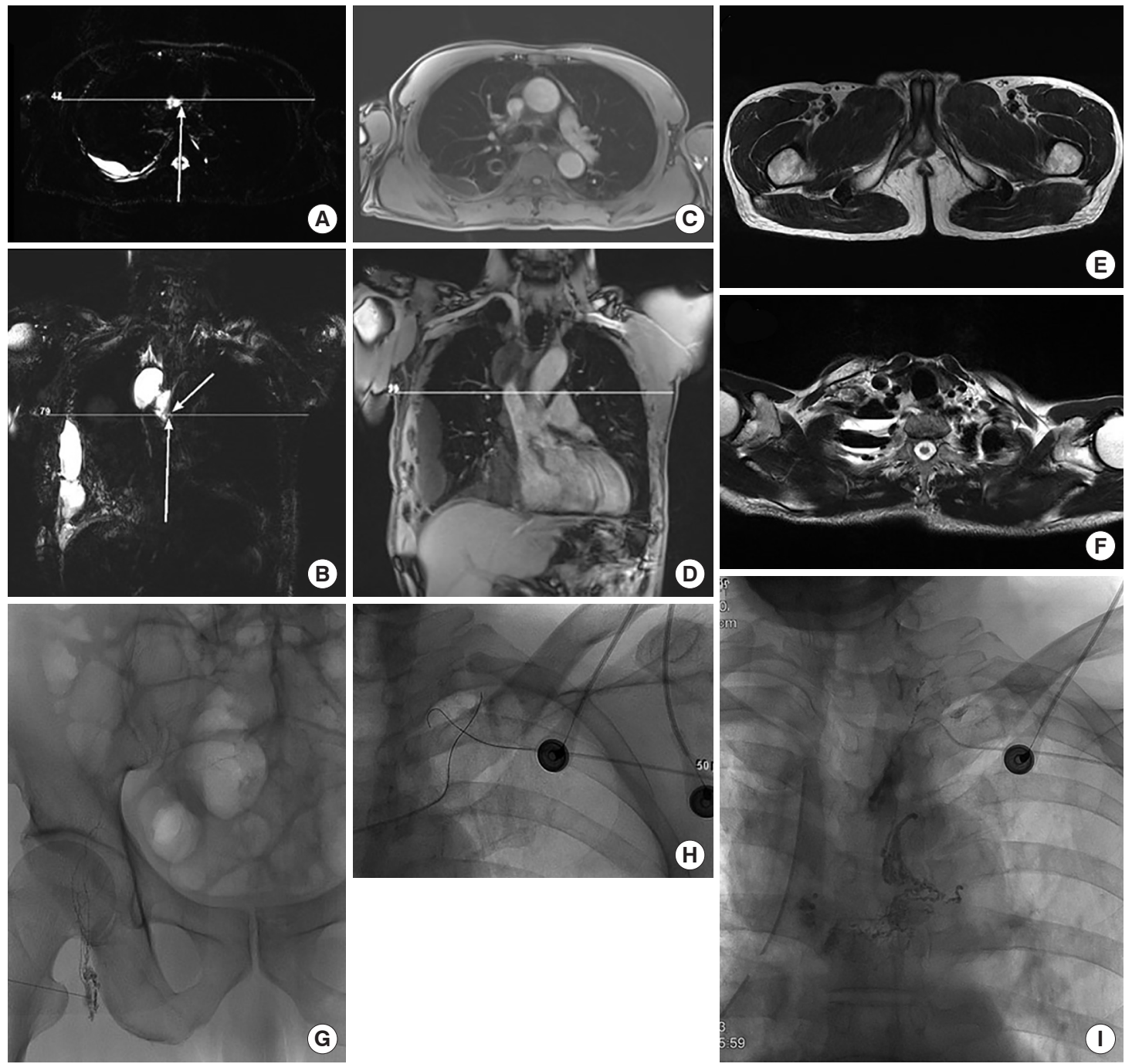

Fig. 11. Images from a representative protocol for non-invasive magnetic resonance (MR) lymphangiography. (A, B) Axial and coronal lymphangiography plane images obtained using a heavily T2-weighted sequence, all with free-breathing status. Lymphangitic leakage (arrows) was suspected at the carina level. (C, D) Fast enhanced images based on a 3D gradient-recalled-echo T1-weighted sequence for obtaining anatomical information. (E, F) T2-weighted images without fat-suppression of the inguinal and periclavicular areas for possible follow-up interventions such as thoracic duct embolization. (G) Lymphatic leakage was suspected at the left side of the carina; therefore, fluoroscopic lymphangiography with the inguinal approach was attempted, but was unsuccessful. (H) A second attempt with the sub-clavicular approach using T2-weighted imaging followed, and contrast leakage was observed at the same site as in the MR lymphangiography image (I).

can be problematic, and significant respiratory complications can occur due to pulmonary oil embolisms or pneumonitis [153]. Invasive CT or MR lymphangiography (MRL) (Fig. 11 ) is also incredibly challenging because image acquisition requires the difficult intervention of an intranodal injection. [154] Conversely, intrinsic contrast can be used for non-invasive MRL [155]. Due to the variations in the central lymphatic structure [156], it is critical to visualize the structure as well as the leakage point for both accurate diagnosis and therapeutic planning [157]. The termination site of the thoracic duct is another feature that needs to be visualized well, be- cause it is where lymphatic leakage often develops, and it is related to supraclavicular lymph node dissection. In addition, when the interventional approach from the femoral side fails, interventional radiologists have to attempt the procedure from the subclavian side, and lymphangiography, particularly for that portion, provides very helpful guidance.

Two important factors should be taken into account for MRL. First, free-breathing should be considered, because lung cancer is frequently diagnosed in elderly patients who find it difficult to hold their breath during acquisition; additionally, lung cancer patients experience significant post-op- 

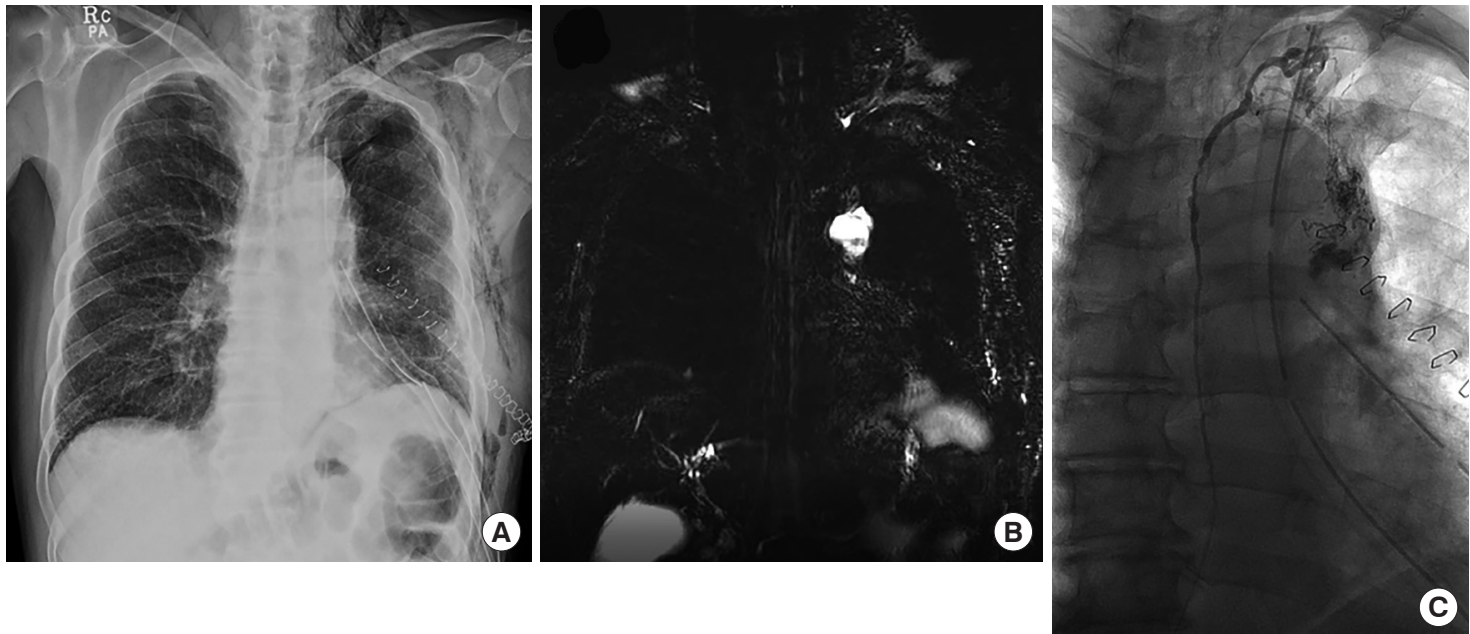

Fig. 12. (A) A case of chylothorax at post-operative day 5 after left upper lobe lobectomy for lung adenocarcinoma. Magnetic resonance lymphangiography (B) revealed an abnormal fluid pocket at the superior aspect of the aortic arch, and a connection to the subclavian part of lymphatic system was noted. Fluoroscopic lymphangiography (C) revealed lymphatic leakage at the corresponding point, which could have been due to a lymphatic injury during para-aortic lymph node dissection.
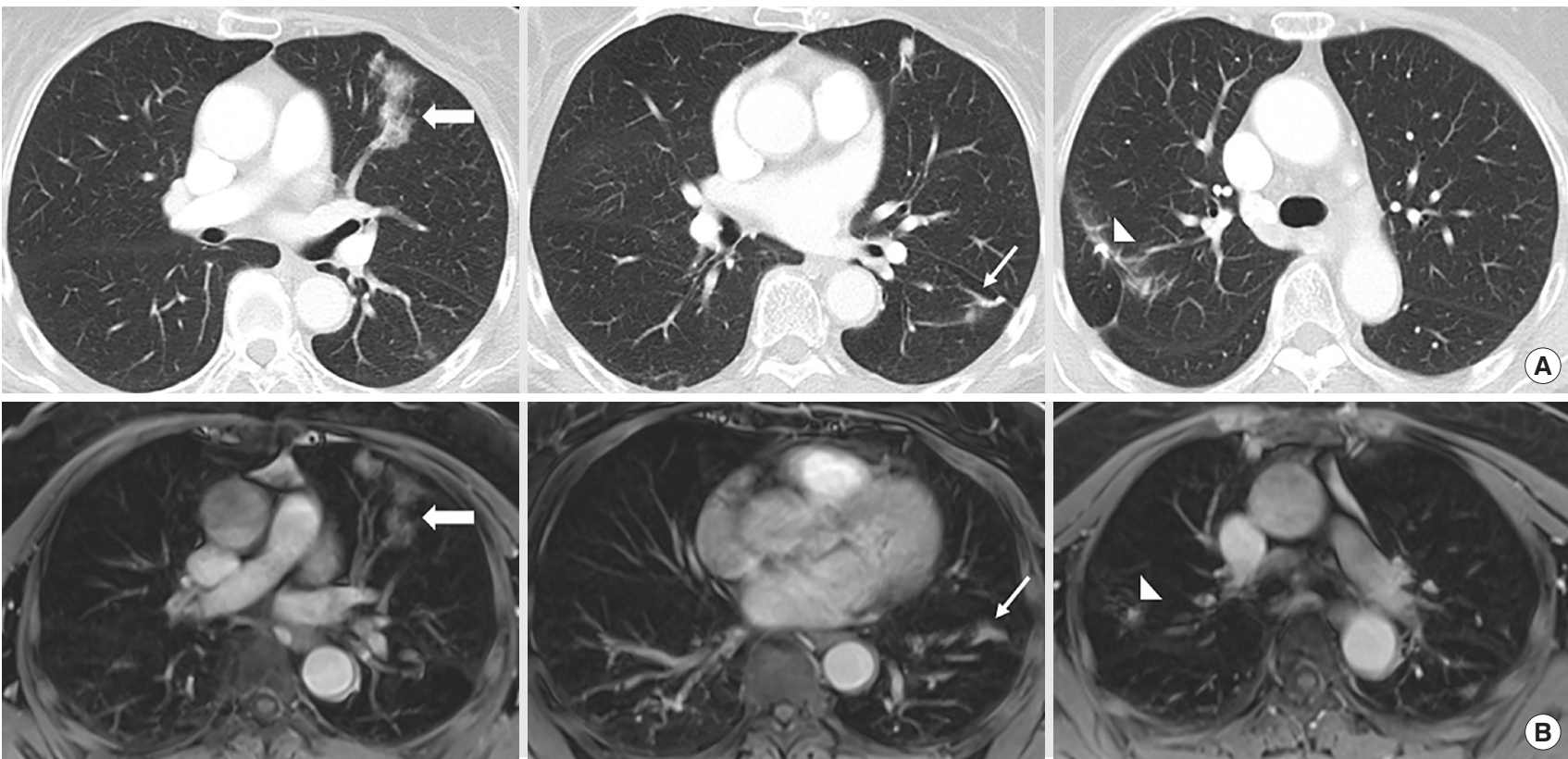

Fig. 13. A 60-year-old male who had undergone right upper and left lower wedge resections for adenocarcinomas. Magnetic resonance imaging was conducted at the 3-month follow-up due to an adverse reaction to the contrast agent. (A) Contrast-enhanced computed tomography images show ground glass opacity in the left upper lobe (thick arrow), with post-operative changes in the left lower lobe (thin arrow) and right upper lobe (arrowhead). (B) Ground glass opacity in the left upper lobe (thick arrow) and post-operative changes in the left lower lobe (thin arrow) and right upper lobe (arrowhead) are also visible on contrast-enhanced T1-weighted gradient-recalled-echo images with fat-suppression.

erative dyspnea. Second, the ingestion of 1 to 3 tablespoons of olive oil is quite useful for improving the quality of lymphangiography images, because it stimulates lymphatic flow [158].

One recent study compared the performance of intranodal lymphangiography and thoracic duct embolization with that of MRL in 50 patients with post-operative chylous leakage in terms of diagnosing leakage and imaging the anatomic details of the lymphatic structures (Fig. 12) [157]. The sensitivity, specificity, and positive and negative predictive values of 
PRECISION AND FUTURE MEDICINE

So Hyeon Bak, et al.
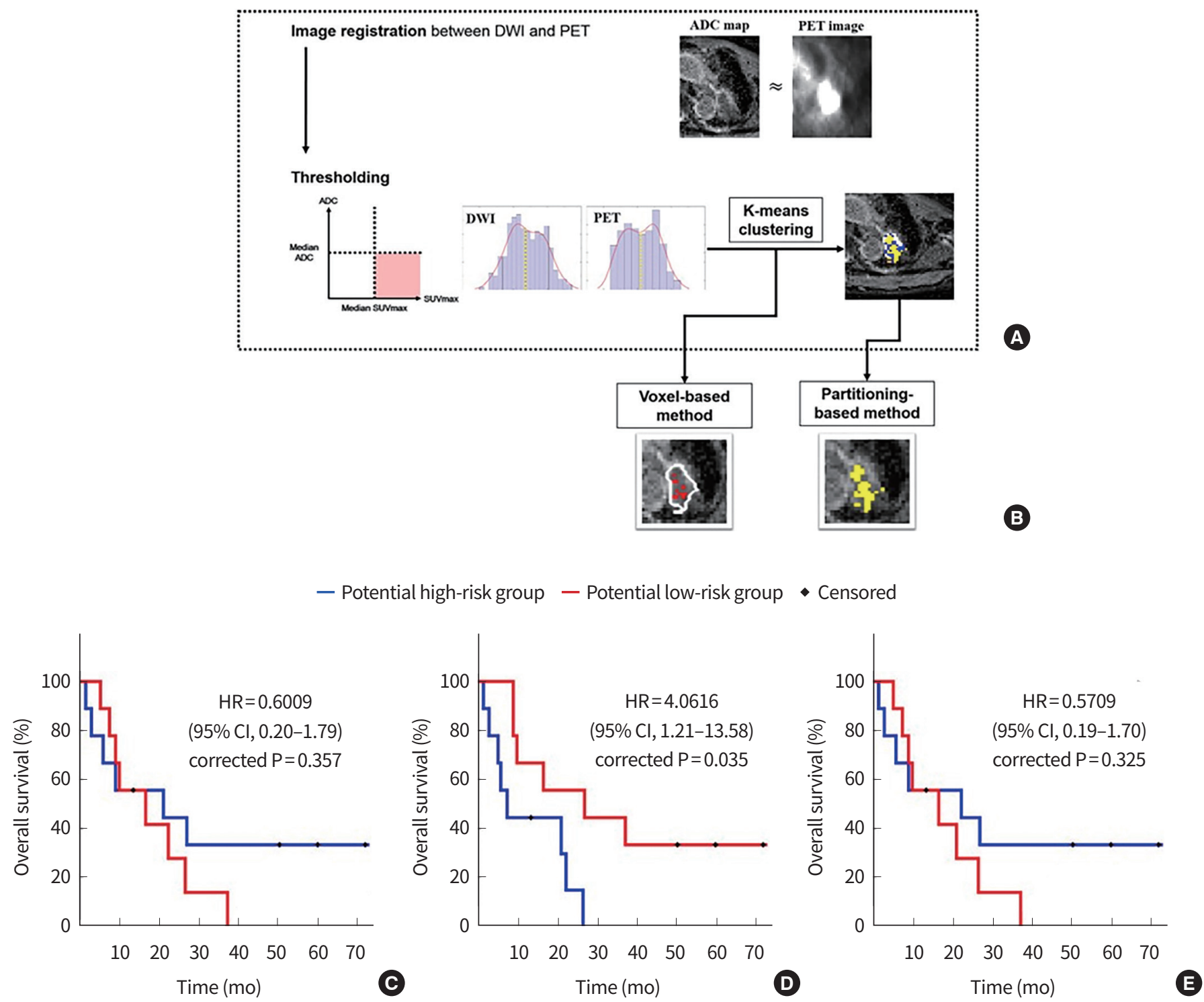

Fig. 14. Multimodal analysis using positron emission tomography (PET) and diffusion-weighted imaging (DWI). (A, B) Overview of the image processing steps. Overall processing includes two parts. Panel $(A)$ involves PET and DWI image registration, thresholding against median values, and k-means clustering. Panel (B) involves computing the hot spot using a voxel-based method (left, using the threshold rule only) and a partitioning-based method (right, using both the threshold rule and clustering). (C, D, E) Results of survival analyses. (C) Kaplan-Meier plot for the whole tumor volume approach. (D) Kaplan-Meier plot for the partitioning-based approach. (E) Kaplan-Meier plot for the voxelwise approach. Reprinted from Kim et al. [164], with permission from Springer Nature. ADC, apparent diffusion coefficient; HR, hazard ratio; $\mathrm{Cl}$, confidence interval.

MRL for leakage detection were $100 \%, 97.1 \%, 100 \%$, and $100 \%$ respectively, and its concordance rate was $97.14 \%$ (95\% $\mathrm{Cl}, 85.08$ to $99.93 ; \mathrm{P}<0.001)$.

\section{Treatment response evaluation}

MRI can be a problem-solving tool during treatment response evaluation, for example, in differentiating between radiation pneumonitis and true progression. Radiation-induced pneumonitis is quite non-specific and sometimes obscures tumor recurrence. According to an article by Jagoda et al. [159], 12 patients with NSCLC stages I-III who were scheduled for radiochemotherapy underwent CE-CT and non-enhanced MRI before and 3, 6, and 12 months after treatment. No significant difference was observed in longitudinal diameter or tumor volume between MRI and $\mathrm{CT}$, and the ADC value for detecting residual malignancy or recurrence was more sensitive than $\mathrm{CT}$ because non-responder lesions had significantly lower ADC values than those of responders. 


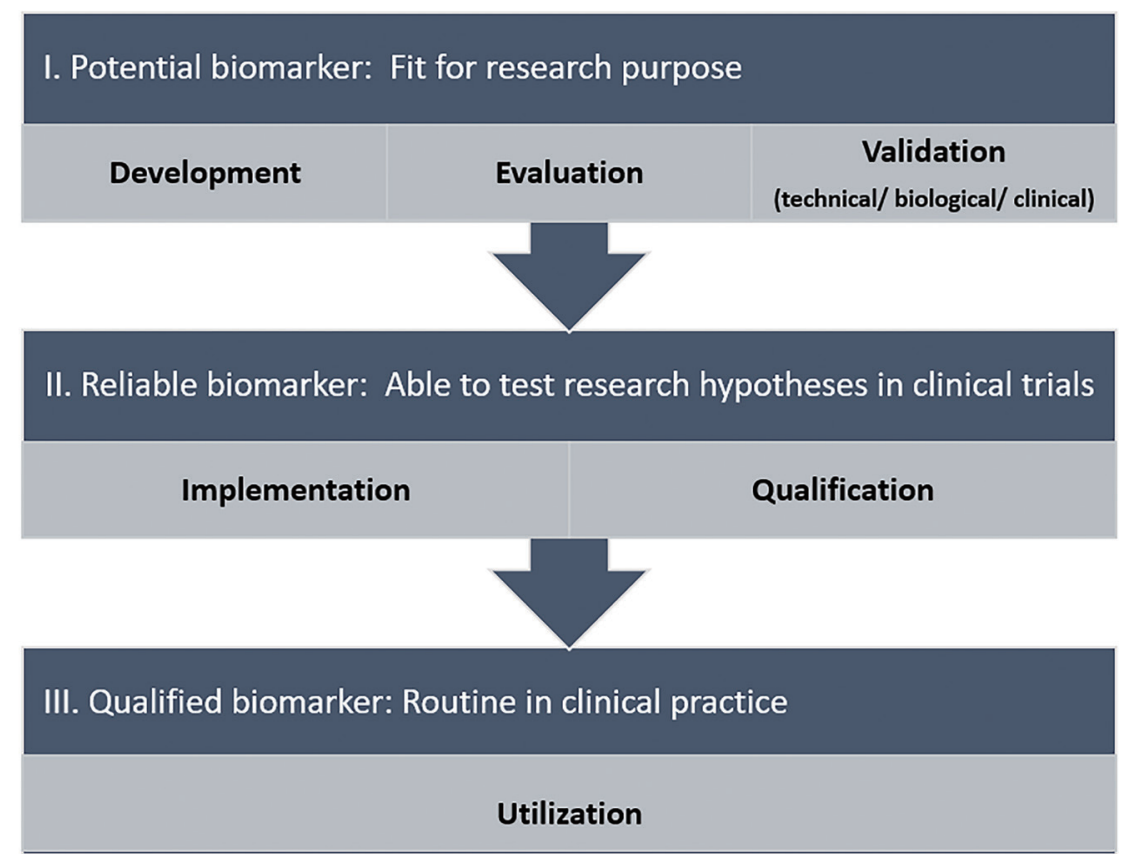

Fig. 15. Schema highlighting the steps in the development of a potential imaging biomarker.

Table 9. Key characteristics and challenges for MR imaging biomarkers

\begin{tabular}{|c|c|c|}
\hline Characteristic & Challenge for MR imaging & Development \\
\hline \multirow[t]{4}{*}{ Sensitivity } & SNR & New sequences \\
\hline & CNR & \\
\hline & Spatial resolution & \\
\hline & Artifacts & \\
\hline Specificity \& biological relevance & $\begin{array}{l}\text { Targeted versus physiological or morphological } \\
\text { imaging }\end{array}$ & $\begin{array}{l}\text { Evaluation of more targeted imaging, e.g., receptor } \\
\text { imaging, targeted nanoparticles }\end{array}$ \\
\hline Robustness & $\begin{array}{l}\text { Variance among imaging systems, manufacturers, } \\
\text { and practices }\end{array}$ & $\begin{array}{l}\text { Multivendor \& multicenter involvement to standardize } \\
\text { data acquisition, reconstruction, and analysis }\end{array}$ \\
\hline \multirow[t]{2}{*}{ Quantifiability \& reproducibility } & $\begin{array}{l}\text { Variance among imaging systems, manufacturers, } \\
\text { and practices }\end{array}$ & $\begin{array}{l}\text { Advanced acquisition and reconstruction to exploit } \\
\text { data redundancy }\end{array}$ \\
\hline & & $\begin{array}{l}\text { Single-sequence MRI to acquire several image } \\
\text { contrasts in a co-registered fashion, e.g., MR } \\
\text { fingerprinting }\end{array}$ \\
\hline Cost-effectiveness & Higher cost than CT and ultrasound & Reduction in scanner time with faster acquisitions \\
\hline
\end{tabular}

MR, magnetic resonance; SNR, signal-to-noise ratio; CNR, contrast-to-noise ratio; MRI, magnetic resonance imaging; CT, computed tomography.

When using $\mathrm{CT}$ for cancer patients, the downside of the recent exponential increase in CT and MRI use is that a sizable proportion of patients experience side-effects due to contrast agents. When these side-effects were categorized into five subgroups based on involved organ and severity, the incidence of severe adverse reactions was quite high [160-163]. However, advanced lung cancer patients must undergo follow-up imaging, regardless of adverse reactions. As MRI re- quires little or no contrast agent use, patients experiencing severe adverse reactions to CT contrast agents could use MRI as a surveillance imaging modality instead (Fig. 13).

For more precise treatment evaluations, multimodal analysis using PET and DWI can be considered [164]. By integrating SUV max $_{\text {ax }}$ and ADC values, we divided the entire tumor volume into four subregions, including necrotic areas and areas indicating high tumor aggressiveness (Fig. 14). Focusing the 


\section{PRECISION AND FUTURE MIEDICINE \\ So Hyeon Bak, et al.}

Table 10. Common thoracic MR artifacts and possible solutions

\begin{tabular}{ll}
\hline Artifacts & \multicolumn{1}{c}{ Solution } \\
\hline Respiratory motion & $\begin{array}{l}\text { Breath-hold imaging (preferred) or respiratory gating. Oxygen administration and patient coaching can } \\
\text { increase breath-hold capability. } \\
\text { ECG gating (preferred over peripheral gating). Should be used selectively as it significantly increases scan } \\
\text { times. }\end{array}$ \\
Ghosting artifact & $\begin{array}{l}\text { Swapping of the phase and frequency encoding directions. Application of saturation bands. } \\
\text { Magnetic susceptibility artifact }\end{array}$ \\
$\begin{array}{l}\text { Using spin echo rather than gradient echo sequences. Decreasing TE when possible. Increasing receiver } \\
\text { bandwidth. }\end{array}$ & Increasing the field-of-view or using the "no-wrap" imaging function.
\end{tabular}

MR, magnetic resonance; ECG, electrocardiogram; TE, echo time.

Table 11. Technical considerations for quantification with MRI

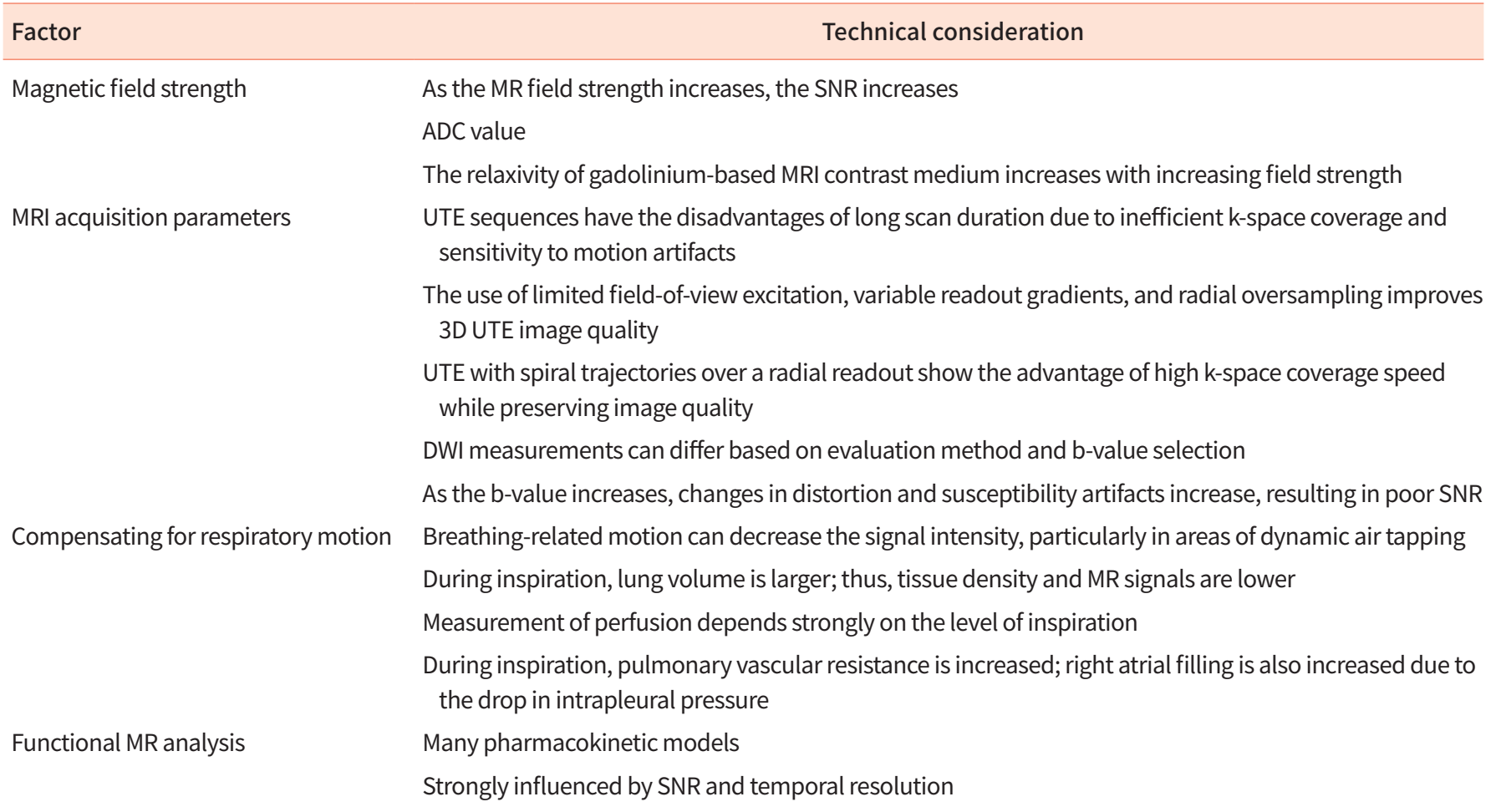

MRI, magnetic resonance imaging; MR, magnetic resonance; ADC, apparent diffusion coefficient; UTE, ultrashort echo time; DWI, diffusion-weighted imaging; SNR, signal-to-noise ratio.

resulting partitioning-based clustering on highly aggressive areas showed better predictive performance for overall survival than whole tumor volume or voxel-based approaches (Fig. 14).

\section{FUTURE DIRECTIONS}

A biomarker is a characteristic that can be measured objectively to indicate normal biological processes, pathological changes, or response to an intervention [165]. Biomarkers can include molecular, histological, radiographic, and physiological characteristics. In terms of imaging, they can include anatomical, functional, and molecular characteristics [166]. Although $\mathrm{CT}$ remains the principal imaging tool for routine pulmonary imaging examinations, MRI has emerged as the clinical standard and has shown enormous potential to transform clinical care for certain patients and indications. In addition, the unique information that current MRI tools provide can be used for mechanistic, hypothesis-driven research in clinical as well as pre-clinical models [6]. 


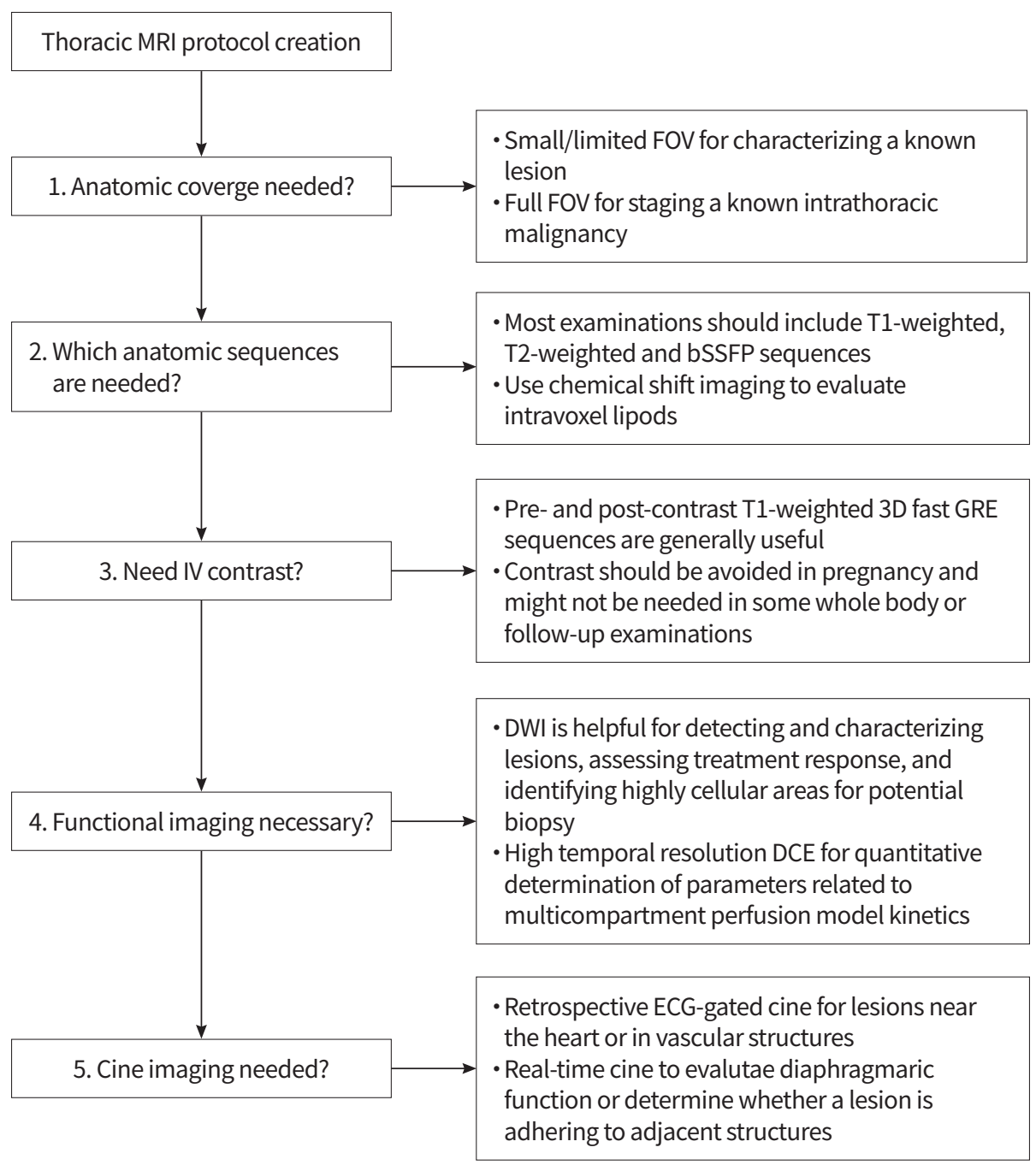

Fig. 16. Building blocks for thoracic magnetic resonance imaging (MRI): challenges, sequences, and protocol design [170]. FOV, field-of-view; bSSFP, balanced steady state free precession; IV, intravenous; GRE, gradient-recalled-echo; DWI, diffusion-weighted imaging; DCE, dynamic contrast-enhanced; ECG, electrocardiogram.

To develop new imaging biomarkers, several steps, often parallel and complementary to one another, need to be undertaken for translation to clinical practice. These can be categorized into the following phases: discovery, development and evaluation, validation, implementation, qualification, and utilization. These phases must also cross two translational gaps, to patients and into practice (Fig. 15) [167]. MRI has many advantages, including superior soft tissue contrast and high spatial resolution, the potential of the use of multiple contrasts in a single examination, and its ability to allow assessment of physiological processes such as vascularization, oxygenation, and diffusion [167]; nevertheless, there are several key characteristics and challenges in using MRI biomarkers (Table 9).

When considering more advanced applications of full- fledged MRI biomarkers, we first need to consider how to obtain high-quality MR data after removing various artifacts (Table 10) [168]. Table 11 lists the vital elements required to maintain technical reproducibility [169].

Most thoracic MRI examinations are performed to answer a specific clinical question that originates during the interpretation of a prior CT or PET examination. Consequently, most thoracic MRI examinations can be tailored to the patient and the clinical questions being addressed in a practical example of personalized medicine. For example, Raptis et al. [170] proposed creating thoracic MRI protocols using five questions (Fig. 16).

Compressed sensing (CS) is an alternative acceleration technique that exploits the inherent sparsity of MRI to reconstruct images by under-sampling k-space data [171]. In con- 
trast to parallel imaging, CS does not require the use of multiple-channel radiofrequency coils, facilitating the translation of the technique across different sites and scanners. Three requirements must be satisfied to ensure good CS image reconstruction: (1) image data must be sparse in either the image domain or a transform domain; (2) the k-space must be randomly under-sampled with variable-density schemes to ensure that the associated artifacts produced during reconstruction are incoherent/noise-like and can be smoothed using the CS algorithm; and (3) a non-linear reconstruction method must be used to enforce sparsity and data fidelity [172]. The reduction in acquisition time offered by CS allows isotropic resolution of ${ }^{3} \mathrm{He}$ and ${ }^{1} \mathrm{H}$ lung MR images acquired in the same breath-hold [173]. CS techniques have also been implemented to enable high temporal resolution gas flow measurements in the upper airways with phase-contrast velocity [174]. The development of these key methods facilitated the clinical translation of this technique for the evaluation of multiple aspects of lung function in several pulmonary disorders.

Artificial intelligence (AI) in imaging has also made great strides in the past few years. Al-based systems are used for tasks that are typically performed by diagnostic radiologists, such as scan quality evaluation, whole lung/nodule segmentation, lesion detection, and disease classification in research settings [175,176]. However, the majority of research-based Al solutions aiding these steps require training with large, diverse datasets, and the Al models need to be tested in real-life settings before routine use in clinical practice.

\section{CONCLUSION}

Until recently, the clinical use of thoracic MRI was limited. However, advanced methods are expanding the opportunities to exploit the advantages of MRI in the evaluation of several common lung disorders. MRI helps to visualize structural and functional lung abnormalities without the need for ionizing radiation, making state-of-the-art MRI techniques an alternative to $\mathrm{CT}$, particularly for pediatric patients, women of child-bearing age, pregnant women, and patients requiring serial follow-up imaging [6].

Multiple challenges remain to be addressed in incorporating pulmonary MRI into routine clinical practice. These include further validation of image-based measures, standardization of image acquisition and analysis, establishment of normal values, demonstration of cost-effectiveness and improved patient outcomes, efficient integration into radiology workflows, and regulatory approval of investigational techniques [4]. Interdisciplinary collaboration between clinicians and scientists with expertise in oncology, imaging, and physiology is needed to address these challenges and prioritize the most useful clinical applications that can expand the role of thoracic MRI in the evaluation and treatment of lung cancer patients.

\section{CONFLICTS OF INTEREST}

No potential conflict of interest relevant to this article was reported.

\section{ACKNOWLEDGMENTS}

This work was supported by Future Medicine $20^{\star} 30$ Project of the Samsung Medical Center (\#SMX1210781) and the National Research Foundation of Korea (NRF) grant funded by the Korea government (MSIT) (NRF-2021R1A4A5032806).

\section{ORCID}

So Hyeon Bak https://orcid.org/0000-0003-1039-7016

Chohee Kim https://orcid.org/0000-0002-3383-8147

Chu Hyun Kim https://orcid.org/0000-0002-3515-5163

Yoshiharu Ohno https://orcid.org/0000-0002-4431-1084

Ho Yun Lee https://orcid.org/0000-0001-9960-5648

\section{AUTHOR CONTRIBUTIONS}

Conception or design: HYL.

Acquisition, analysis, or interpretation of data: $\mathrm{SHB}, \mathrm{CK}, \mathrm{CHK}$, HYL.

Drafting the work or revising: SHB, CK, CHK, YO, HYL.

Final approval of the manuscript: SHB, CK, CHK, YO, HYL.

\section{REFERENCES}

1. Halpenny D, O'Dwyer E, Girshman J, Ginsberg MS. Imaging of novel oncologic treatments in lung cancer part 1: systemic therapies. J Thorac Imaging 2020;35:26-36.

2. Lee G, Lee HY, Park H, Schiebler ML, van Beek E, Ohno Y, et al. Radiomics and its emerging role in lung cancer research, imaging biomarkers and clinical management: state of the art. Eur J Radiol 2017;86:297-307.

3. Bergin CJ, Glover GM, Pauly J. Magnetic resonance imaging of lung parenchyma. J Thorac Imaging 1993;8:12- 
7.

4. Gefter WB, Lee KS, Schiebler ML, Parraga G, Seo JB, Ohno Y, et al. Pulmonary functional imaging: part 2. State-of-theart clinical applications and opportunities for improved patient care. Radiology 2021;299:524-38.

5. Hatabu H, Chen Q, Stock KW, Gefter WB, Itoh H. Fast magnetic resonance imaging of the lung. Eur J Radiol 1999; 29:114-32.

6. Hatabu H, Ohno Y, Gefter WB, Parraga G, Madore B, Lee $\mathrm{KS}$, et al. Expanding applications of pulmonary MRI in the clinical evaluation of lung disorders: Fleischner Society position paper. Radiology 2020;297:286-301.

7. Mayo JR. MR imaging of pulmonary parenchyma. Magn Reson Imaging Clin N Am 2000;8:105-23.

8. Ohno Y, Hanamatsu S, Obama Y, Ueda T, Ikeda H, Hattori $\mathrm{H}$, et al. Overview of MRI for pulmonary functional imaging. Br J Radiol 2022;93:20201053.

9. Ohno Y, Seo JB, Parraga G, Lee KS, Gefter WB, Fain SB, et al. Pulmonary functional imaging: part 1-state-of-theart technical and physiologic underpinnings. Radiology 2021;299:508-23.

10. Schiebler ML, Parraga G, Gefter WB, Madore B, Lee KS, Ohno Y, et al. Synopsis from expanding applications of pulmonary MRI in the clinical evaluation of lung disorders: Fleischner Society position paper. Chest 2021;159:492-5.

11. Tanaka Y, Ohno Y, Hanamatsu S, Obama Y, Ueda T, Ikeda $\mathrm{H}$, et al. State-of-the-art MR imaging for thoracic diseases. Magn Reson Med Sci 2022;21:212-34.

12. Biederer J, Ohno Y, Hatabu H, Schiebler ML, van Beek E, Vogel-Claussen J, et al. Screening for lung cancer: does MRI have a role? Eur J Radiol 2017;86:353-60.

13. Ciliberto M, Kishida Y, Seki S, Yoshikawa T, Ohno Y. Update of MR imaging for evaluation of lung cancer. Radiol Clin North Am 2018;56:437-69.

14. Fain SB, Korosec FR, Holmes JH, O'Halloran R, Sorkness RL, Grist TM. Functional lung imaging using hyperpolarized gas MRI. J Magn Reson Imaging 2007;25:910-23.

15. Johns CS, Swift AJ, Hughes P, Ohno Y, Schiebler M, Wild JM. Pulmonary MR angiography and perfusion imaging: a review of methods and applications. Eur J Radiol 2017; 86:361-70.

16. Kim HS, Lee KS, Ohno Y, van Beek EJ, Biederer J. PET/CT versus MRI for diagnosis, staging, and follow-up of lung cancer. J Magn Reson Imaging 2015;42:247-60.

17. Koyama H, Ohno Y, Seki S, Nishio M, Yoshikawa T, Matsumoto $\mathrm{S}$, et al. Magnetic resonance imaging for lung cancer. J Thorac Imaging 2013;28:138-50.
18. Kruger SJ, Nagle SK, Couch MJ, Ohno Y, Albert M, Fain SB. Functional imaging of the lungs with gas agents. J Magn Reson Imaging 2016;43:295-315.

19. Liszewski MC, Hersman FW, Altes TA, Ohno Y, Ciet P, Warfield SK, et al. Magnetic resonance imaging of pediatric lung parenchyma, airways, vasculature, ventilation, and perfusion: state of the art. Radiol Clin North Am 2013;51: 555-82.

20. Ohno Y. New applications of magnetic resonance imaging for thoracic oncology. Semin Respir Crit Care Med 2014; 35:27-40.

21. Ohno Y, Chen Q, Hatabu H. Oxygen-enhanced magnetic resonance ventilation imaging of lung. Eur J Radiol 2001; 37:164-71.

22. Ohno Y, Kauczor HU, Hatabu H, Seo JB, van Beek EJR; International Workshop for Pulmonary Functional Imaging (IWPFI). MRI for solitary pulmonary nodule and mass assessment: current state of the art. J Magn Reson Imaging 2018;47:1437-58.

23. Ohno Y, Koyama H, Lee HY, Miura S, Yoshikawa T, Sugimura K. Contrast-enhanced CT- and MRI-based perfusion assessment for pulmonary diseases: basics and clinical applications. Diagn Interv Radiol 2016;22:40721.

24. Ohno Y, Koyama H, Lee HY, Yoshikawa T, Sugimura K. Magnetic resonance imaging (MRI) and positron emission tomography (PET)/MRI for lung cancer staging. J Thorac Imaging 2016;31:215-27.

25. Ohno Y, Koyama H, Yoshikawa T, Matsumoto S, Sugimura K. Lung cancer assessment using MR imaging: an update. Magn Reson Imaging Clin N Am 2015;23:231-44.

26. Ohno Y, Koyama H, Yoshikawa T, Nishio M, Matsumoto S, Iwasawa T, et al. Pulmonary magnetic resonance imaging for airway diseases. J Thorac Imaging 2011;26:30116.

27. Ohno Y, Koyama H, Yoshikawa T, Seki S. State-of-the-art imaging of the lung for connective tissue disease (CTD). Curr Rheumatol Rep 2015;17:69.

28. Ohno Y, Nishio M, Koyama H, Miura S, Yoshikawa T, Matsumoto $\mathrm{S}$, et al. Dynamic contrast-enhanced CT and MRI for pulmonary nodule assessment. AJR Am J Roentgenol 2014;202:515-29.

29. Ohno Y, Sugimura K, Hatabu H. MR imaging of lung cancer. Eur J Radiol 2002;44:172-81.

30. Ohno Y, Yoshikawa T, Kishida Y, Seki S, Karabulut N. Unenhanced and contrast-enhanced MR angiography and perfusion imaging for suspected pulmonary thrombo- 
embolism. AJR Am J Roentgenol 2017;208:517-30.

31. Sieren JC, Ohno Y, Koyama H, Sugimura K, McLennan G. Recent technological and application developments in computed tomography and magnetic resonance imaging for improved pulmonary nodule detection and lung cancer staging. J Magn Reson Imaging 2010;32:1353-69.

32. Tsuchiya N, van Beek EJ, Ohno Y, Hatabu H, Kauczor HU, Swift A, et al. Magnetic resonance angiography for the primary diagnosis of pulmonary embolism: a review from the international workshop for pulmonary functional imaging. World J Radiol 2018;10:52-64.

33. Wielputz MO, Triphan S, Ohno Y, Jobst BJ, Kauczor HU. Outracing lung signal decay: potential of ultrashort echo time MRI. Rofo 2019;191:415-23.

34. Webb WR, Gatsonis C, Zerhouni EA, Heelan RT, Glazer $\mathrm{GM}$, Francis IR, et al. CT and MR imaging in staging nonsmall cell bronchogenic carcinoma: report of the Radiologic Diagnostic Oncology Group. Radiology 1991;178: 705-13.

35. Ohno Y, Kishida Y, Seki S, Yui M, Miyazaki M, Koyama H, et al. Amide proton transfer-weighted imaging to differentiate malignant from benign pulmonary lesions: comparison with diffusion-weighted imaging and FDG-PET/ CT. J Magn Reson Imaging 2018;47:1013-21.

36. Ohno Y, Yui M, Koyama H, Yoshikawa T, Seki S, Ueno Y, et al. Chemical exchange saturation transfer MR imaging: preliminary results for differentiation of malignant and benign thoracic lesions. Radiology 2016;279:578-89.

37. Fink C, Puderbach M, Biederer J, Fabel M, Dietrich O, Kauczor HU, et al. Lung MRI at 1.5 and 3 Tesla: observer preference study and lesion contrast using five different pulse sequences. Invest Radiol 2007;42:377-83.

38. Campbell-Washburn AE, Ramasawmy R, Restivo MC, Bhattacharya I, Basar B, Herzka DA, et al. Opportunities in interventional and diagnostic imaging by using high-performance low-field-strength MRI. Radiology 2019;293:38493.

39. Yi CA, Jeon TY, Lee KS, Lee JH, Seo JB, Kim YK, et al. 3-T MRI: usefulness for evaluating primary lung cancer and small nodules in lobes not containing primary tumors. AJR Am J Roentgenol 2007;189:386-92.

40. Hori M, Hagiwara A, Goto M, Wada A, Aoki S. Low-field magnetic resonance imaging: its history and renaissance. Invest Radiol 2021;56:669-79.

41. Koyama H, Ohno Y, Aoyama N, Onishi Y, Matsumoto K, Nogami M, et al. Comparison of STIR turbo SE imaging and diffusion-weighted imaging of the lung: capability for detection and subtype classification of pulmonary adenocarcinomas. Eur Radiol 2010;20:790-800.

42. Koyama H, Ohno Y, Seki S, Nishio M, Yoshikawa T, Matsumoto $S$, et al. Value of diffusion-weighted MR imaging using various parameters for assessment and characterization of solitary pulmonary nodules. Eur J Radiol 2015; 84:509-15.

43. Ohno Y, Koyama H, Onishi Y, Takenaka D, Nogami M, Yoshikawa T, et al. Non-small cell lung cancer: whole-body MR examination for M-stage assessment. Utility for wholebody diffusion-weighted imaging compared with integrated FDG PET/CT. Radiology 2008;248:643-54.

44. Ohno Y, Koyama H, Yoshikawa T, Matsumoto K, Aoyama $\mathrm{N}$, Onishi Y, et al. Diffusion-weighted MRI versus 18F-FDG $\mathrm{PET} / \mathrm{CT}$ : performance as predictors of tumor treatment response and patient survival in patients with non-small cell lung cancer receiving chemoradiotherapy. AJR Am J Roentgenol 2012;198:75-82.

45. Ohno Y, Koyama H, Yoshikawa T, Nishio M, Aoyama N, Onishi Y, et al. $\mathrm{N}$ stage disease in patients with non-small cell lung cancer: efficacy of quantitative and qualitative assessment with STIR turbo spin-echo imaging, diffusion-weighted MR imaging, and fluorodeoxyglucose PET/CT. Radiology 2011;261:605-15.

46. Takenaka D, Ohno Y, Matsumoto K, Aoyama N, Onishi Y, Koyama $\mathrm{H}$, et al. Detection of bone metastases in nonsmall cell lung cancer patients: comparison of wholebody diffusion-weighted imaging (DWI), whole-body MR imaging without and with DWI, whole-body FDG-PET/ $\mathrm{CT}$, and bone scintigraphy. J Magn Reson Imaging 2009; 30:298-308.

47. Yabuuchi H, Hatakenaka M, Takayama K, Matsuo Y, Sunami S, Kamitani T, et al. Non-small cell lung cancer: detection of early response to chemotherapy by using contrast-enhanced dynamic and diffusion-weighted MR imaging. Radiology 2011;261:598-604.

48. Mikayama R, Yabuuchi H, Sonoda S, Kobayashi K, Nagatomo K, Kimura M, et al. Comparison of intravoxel incoherent motion diffusion-weighted imaging between turbo spin-echo and echo-planar imaging of the head and neck. Eur Radiol 2018;28:316-24.

49. Ohno Y, Koyama H, Yoshikawa T, Takenaka D, Kassai Y, Yui $M$, et al. Diffusion-weighted MR imaging using FASE sequence for 3T MR system: preliminary comparison of capability for $\mathrm{N}$-stage assessment by means of diffusion-weighted MR imaging using EPI sequence, STIR FASE imaging and FDG PET/CT for non-small cell lung cancer 
patients. Eur J Radiol 2015;84:2321-31.

50. Koh DM, Collins DJ. Diffusion-weighted MRI in the body: applications and challenges in oncology. AJR Am J Roentgenol 2007;188:1622-35.

51. Koh DM, Collins DJ, Orton MR. Intravoxel incoherent motion in body diffusion-weighted MRI: reality and challenges. AJR Am J Roentgenol 2011;196:1351-61.

52. Morone M, Bali MA, Tunariu N, Messiou C, Blackledge M, Grazioli L, et al. Whole-body MRI: current applications in oncology. AJR Am J Roentgenol 2017;209:W336-49.

53. Padhani AR, Koh DM, Collins DJ. Whole-body diffusionweighted MR imaging in cancer: current status and research directions. Radiology 2011;261:700-18.

54. Le Bihan D, Breton E, Lallemand D, Grenier P, Cabanis E, Laval-Jeantet M. MR imaging of intravoxel incoherent motions: application to diffusion and perfusion in neurologic disorders. Radiology 1986;161:401-7.

55. Le Bihan D, Breton E, Lallemand D, Aubin ML, Vignaud J, Laval-Jeantet M. Separation of diffusion and perfusion in intravoxel incoherent motion MR imaging. Radiology 1988; 168:497-505.

56. Ohno Y, Koyama H, Yoshikawa T, Takenaka D, Seki S, Yui M, et al. Three-way comparison of whole-body MR, coregistered whole-body FDG PET/MR, and integrated wholebody FDG PET/CT imaging: TNM and stage assessment capability for non-small cell lung cancer patients. Radiology 2015;275:849-61.

57. Ohno Y, Nishio M, Koyama H, Yoshikawa T, Matsumoto S, Takenaka D, et al. Comparison of the utility of wholebody MRI with and without contrast-enhanced Quick 3D and double RF fat suppression techniques, conventional whole-body MRI, PET/CT and conventional examination for assessment of recurrence in NSCLC patients. Eur J Radiol 2013;82:2018-27.

58. Ohno Y, Takeshi Y, Takenaka D, Koyama H, Aoyagi K, Yui M. Comparison of diagnostic accuracy for TNM stage among whole-body MRI and coregistered PET/MRI using 1.5-T and 3-T MRI systems and integrated PET/CT for non-small cell lung cancer. AJR Am J Roentgenol 2020; 215:1191-8.

59. Ohno Y, Yoshikawa T, Kishida Y, Seki S, Koyama H, Yui M, et al. Diagnostic performance of different imaging modalities in the assessment of distant metastasis and local recurrence of tumor in patients with non-small cell lung cancer. J Magn Reson Imaging 2017;46:1707-17.

60. Bell LC, Johnson KM, Fain SB, Wentland A, Drees R, Johnson RA, et al. Simultaneous MRI of lung structure and perfusion in a single breathhold. J Magn Reson Imaging 2015;41:52-9.

61. Burris NS, Johnson KM, Larson PE, Hope MD, Nagle SK, Behr SC, et al. Detection of small pulmonary nodules with ultrashort echo time sequences in oncology patients by using a PET/MR system. Radiology 2016;278:239-46.

62. Ohno Y, Koyama H, Yoshikawa T, Kishida Y, Seki S, Takenaka $D$, et al. Standard-, reduced-, and no-dose thin-section radiologic examinations: comparison of capability for nodule detection and nodule type assessment in patients suspected of having pulmonary nodules. Radiology 2017;284:562-73.

63. Ohno Y, Koyama H, Yoshikawa T, Seki S, Takenaka D, Yui $M$, et al. Pulmonary high-resolution ultrashort TE MR imaging: comparison with thin-section standard- and low-dose computed tomography for the assessment of pulmonary parenchyma diseases. J Magn Reson Imaging 2016;43:512-32.

64. Ohno Y, Yui M, Chen Y, Kishida Y, Seki S, Yoshikawa T. Gadolinium-based blood volume mapping from MRI with ultrashort TE versus CT and SPECT for predicting postoperative lung function in patients with non-small cell lung cancer. AJR Am J Roentgenol 2019;212:57-66.

65. Guivel-Scharen V, Sinnwell T, Wolff SD, Balaban RS. Detection of proton chemical exchange between metabolites and water in biological tissues. J Magn Reson 1998; 133:36-45.

66. van Zijl PC, Yadav NN. Chemical exchange saturation transfer (CEST): what is in a name and what isn't? Magn Reson Med 2011;65:927-48.

67. National Lung Screening Trial Research Team, Aberle DR, Adams AM, Berg CD, Black WC, Clapp JD, et al. Reduced lung-cancer mortality with low-dose computed tomographic screening. N Engl J Med 2011;365:395-409.

68. American College of Radiology. Lung CT Screening Reporting and Data System (Lung-RADS) [Internet]. Reston (VA): American College of Radiology; 2022 [cited 2022 Jan 27]. Available from: https://www.acr.org/Clinical-Resources/Reporting-and-Data-Systems/Lung-Rads.

69. Kim TJ, Kim CH, Lee HY, Chung MJ, Shin SH, Lee KJ, et al. Management of incidental pulmonary nodules: current strategies and future perspectives. Expert Rev Respir Med 2020;14:173-94.

70. Koyama H, Ohno Y, Kono A, Takenaka D, Maniwa Y, Nishimura $Y$, et al. Quantitative and qualitative assessment of non-contrast-enhanced pulmonary MR imaging for management of pulmonary nodules in 161 subjects. 
Eur Radiol 2008;18:2120-31.

71. Cieszanowski A, Lisowska A, Dabrowska M, Korczynski P, Zukowska M, Grudzinski IP, et al. MR imaging of pulmonary nodules: detection rate and accuracy of size estimation in comparison to computed tomography. PLoS One 2016;11:e0156272.

72. Dewes P, Frellesen C, Al-Butmeh F, Albrecht MH, Scholtz JE, Metzger SC, et al. Comparative evaluation of noncontrast CAIPIRINHA-VIBE 3T-MRI and multidetector CT for detection of pulmonary nodules: in vivo evaluation of diagnostic accuracy and image quality. Eur J Radiol 2016;85:193-8

73. Meier-Schroers M, Kukuk G, Homsi R, Skowasch D, Schild $\mathrm{HH}$, Thomas D. MRI of the lung using the PROPELLER technique: artifact reduction, better image quality and improved nodule detection. Eur J Radiol 2016;85: 707-13.

74. Meier-Schroers M, Homsi R, Schild HH, Thomas D. Lung cancer screening with MRI: characterization of nodules with different non-enhanced MRI sequences. Acta Radiol 2019;60:168-76.

75. Wang YX, Lo GG, Yuan J, Larson PE, Zhang X. Magnetic resonance imaging for lung cancer screen. J Thorac Dis 2014;6:1340-8.

76. Huang YS, Niisato E, Su MM, Benkert T, Hsu HH, Shih JY, et al. Detecting small pulmonary nodules with spiral ultrashort echo time sequences in 1.5 T MRI. MAGMA 2021; 34:399-409.

77. Feng H, Shi G, Liu H, Du Y, Zhang N, Wang Y. The value of PETRA in pulmonary nodules of $<3 \mathrm{~cm}$ among patients with lung cancer. Front Oncol 2021;11:649625.

78. MacMahon H, Naidich DP, Goo JM, Lee KS, Leung A, Mayo JR, et al. Guidelines for management of incidental pulmonary nodules detected on $\mathrm{CT}$ images: from the Fleischner Society 2017. Radiology 2017;284:228-43.

79. Meier-Schroers M, Homsi R, Gieseke J, Schild HH, Thomas D. Lung cancer screening with MRI: evaluation of MRI for lung cancer screening by comparison of LDCT- and MRIderived Lung-RADS categories in the first two screening rounds. Eur Radiol 2019;29:898-905.

80. Grabler P, Sighoko D, Wang L, Allgood K, Ansell D. Recall and cancer detection rates for screening mammography: finding the sweet spot. AJR Am J Roentgenol 2017; 208:208-13.

81. Sommer G, Tremper J, Koenigkam-Santos M, Delorme S, Becker N, Biederer J, et al. Lung nodule detection in a high-risk population: comparison of magnetic reso- nance imaging and low-dose computed tomography. Eur J Radiol 2014;83:600-5.

82. Christensen JA, Nathan MA, Mullan BP, Hartman TE, Swensen SJ, Lowe VJ. Characterization of the solitary pulmonary nodule: 18F-FDG PET versus nodule-enhancement CT. AJR Am J Roentgenol 2006;187:1361-7.

83. Lowe VJ, Duhaylongsod FG, Patz EF, Delong DM, Hoffman JM, Wolfe WG, et al. Pulmonary abnormalities and PET data analysis: a retrospective study. Radiology 1997; 202:435-9.

84. Lowe VJ, Fletcher JW, Gobar L, Lawson M, Kirchner P, Valk $P$, et al. Prospective investigation of positron emission tomography in lung nodules. J Clin Oncol 1998;16: 1075-84.

85. Goo JM, Im JG, Do KH, Yeo JS, Seo JB, Kim HY, et al. Pulmonary tuberculoma evaluated by means of FDG PET: findings in 10 cases. Radiology 2000;216:117-21.

86. Cheran SK, Nielsen ND, Patz EF Jr. False-negative findings for primary lung tumors on FDG positron emission tomography: staging and prognostic implications. AJR Am J Roentgenol 2004;182:1129-32.

87. Nomori H, Watanabe K, Ohtsuka T, Naruke T, Suemasu K, Uno K. Evaluation of F-18 fluorodeoxyglucose (FDG) PET scanning for pulmonary nodules less than $3 \mathrm{~cm}$ in diameter, with special reference to the CT images. Lung Cancer 2004;45:19-27.

88. Mori T, Nomori H, Ikeda K, Kawanaka K, Shiraishi S, Katahira K, et al. Diffusion-weighted magnetic resonance imaging for diagnosing malignant pulmonary nodules/ masses: comparison with positron emission tomography. J Thorac Oncol 2008;3:358-64.

89. Satoh S, Kitazume Y, Ohdama S, Kimula Y, Taura S, Endo Y. Can malignant and benign pulmonary nodules be differentiated with diffusion-weighted MRI? AJR Am J Roentgenol 2008;191:464-70.

90. Uto T, Takehara Y, Nakamura Y, Naito T, Hashimoto D, Inui N, et al. Higher sensitivity and specificity for diffusion-weighted imaging of malignant lung lesions without apparent diffusion coefficient quantification. Radiology 2009;252:247-54.

91. Ohba Y, Nomori H, Mori T, Shiraishi K, Namimoto T, Katahira K. Diffusion-weighted magnetic resonance for pulmonary nodules: 1.5 vs. 3 Tesla. Asian Cardiovasc Thorac Ann 2011;19:108-14.

92. Coolen J, Vansteenkiste J, De Keyzer F, Decaluwe H, De Wever W, Deroose C, et al. Characterisation of solitary pulmonary lesions combining visual perfusion and quantita- 
tive diffusion MR imaging. Eur Radiol 2014;24:531-41.

93. Usuda K, Sagawa M, Motono N, Ueno M, Tanaka M, Machida $Y$, et al. Diagnostic performance of diffusion weighted imaging of malignant and benign pulmonary nodules and masses: comparison with positron emission tomography. Asian Pac J Cancer Prev 2014;15:462935.

94. Besson FL, Fernandez B, Faure S, Mercier O, Seferian A, Blanchet $E$, et al. Diffusion-weighted imaging voxelwisematched analyses of lung cancer at 3.0-T PET/MRI: reverse phase encoding approach for echo-planar imaging distortion correction. Radiology 2020;295:692-700.

95. Ohno Y, Hatabu H, Takenaka D, Adachi S, Kono M, Sugimura K. Solitary pulmonary nodules: potential role of dynamic MR imaging in management initial experience. Radiology 2002;224:503-11.

96. Ohno Y, Koyama H, Takenaka D, Nogami M, Maniwa Y, Nishimura Y, et al. Dynamic MRI, dynamic multidetectorrow computed tomography (MDCT), and coregistered 2-[fluorine-18]-fluoro-2-deoxy-D-glucose-positron emission tomography (FDG-PET)/CT: comparative study of capability for management of pulmonary nodules. J Magn Reson Imaging 2008;27:1284-95.

97. Ogihara Y, Ashizawa K, Hayashi H, Nagayasu T, Hayashi T, Honda S, et al. Progressive massive fibrosis in patients with pneumoconiosis: utility of MRI in differentiating from lung cancer. Acta Radiol 2018;59:72-80.

98. Qi LP, Chen KN, Zhou XJ, Tang L, Liu YL, Li XT, et al. Conventional MRI to detect the differences between masslike tuberculosis and lung cancer. J Thorac Dis 2018;10: 5673-84.

99. Sakai F, Sone S, Maruyama A, Kawai T, Imai S, Aoki J, et al. Thin-rim enhancement in Gd-DTPA-enhanced magnetic resonance images of tuberculoma: a new finding of potential differential diagnostic importance. J Thorac Imaging 1992;7:64-9.

100. Bourgouin PM, McLoud TC, Fitzgibbon JF, Mark EJ, Shepard JA, Moore EM, et al. Differentiation of bronchogenic carcinoma from postobstructive pneumonitis by magnetic resonance imaging: histopathologic correlation. J Thorac Imaging 1991;6:22-7.

101. Ohno Y, Adachi S, Kono M, Kusumoto M, Motoyama A, Sugimura K. Predicting the prognosis of non-small cell lung cancer patient treated with conservative therapy using contrast-enhanced MR imaging. Eur Radiol 2000; 10:1770-81.

102. Kono M, Adachi S, Kusumoto M, Sakai E. Clinical utility of Gd-DTPA-enhanced magnetic resonance imaging in lung cancer. J Thorac Imaging 1993;8:18-26.

103. Yang RM, Li L, Wei XH, Guo YM, Huang YH, Lai LS, et al. Differentiation of central lung cancer from atelectasis: comparison of diffusion-weighted MRI with PET/CT. PLoS One 2013;8:e60279.

104. Shen G, Jia Z, Deng H. Apparent diffusion coefficient values of diffusion-weighted imaging for distinguishing focal pulmonary lesions and characterizing the subtype of lung cancer: a meta-analysis. Eur Radiol 2016;26:556-66.

105. Usuda K, Iwai S, Yamagata A, Sekimura A, Motono N, Matoba $\mathrm{M}$, et al. Relationships and qualitative evaluation between diffusion-weighted imaging and pathologic findings of resected lung cancers. Cancers (Basel) 2020;12: 1194.

106. Razek AA, Fathy A, Gawad TA. Correlation of apparent diffusion coefficient value with prognostic parameters of lung cancer. J Comput Assist Tomogr 2011;35:248-52.

107. Lee HY, Jeong JY, Lee KS, Yi CA, Kim BT, Kang H, et al. Histopathology of lung adenocarcinoma based on new IASLC/ATS/ERS classification: prognostic stratification with functional and metabolic imaging biomarkers. J Magn Reson Imaging 2013;38:905-13.

108. Kanauchi N, Oizumi H, Honma T, Kato H, Endo M, Suzuki $\mathrm{J}$, et al. Role of diffusion-weighted magnetic resonance imaging for predicting of tumor invasiveness for clinical stage IA non-small cell lung cancer. Eur J Cardiothorac Surg 2009;35:706-10.

109. Carter BW, Lichtenberger JP 3rd, Benveniste MK, de Groot PM, Wu CC, Erasmus JJ, et al. Revisions to the TNM staging of lung cancer: rationale, significance, and clinical application. Radiographics 2018;38:374-91.

110. Tanoue LT. Lung cancer staging. Clin Chest Med 2020; 41:161-74.

111. Tang W, Wu N, OuYang H, Huang Y, Liu L, Li M. The presurgical T staging of non-small cell lung cancer: efficacy comparison of 64-MDCT and 3.0 T MRI. Cancer Imaging 2015;15:14.

112. Sakai S, Murayama S, Murakami J, Hashiguchi N, Masuda K. Bronchogenic carcinoma invasion of the chest wall: evaluation with dynamic cine MRI during breathing. J Comput Assist Tomogr 1997;21:595-600.

113. Ohno Y, Adachi S, Motoyama A, Kusumoto M, Hatabu H, Sugimura K, et al. Multiphase ECG-triggered 3D contrast-enhanced MR angiography: utility for evaluation of hilar and mediastinal invasion of bronchogenic carcinoma. J Magn Reson Imaging 2001;13:215-24. 
114. Zhang Y, Kwon W, Lee HY, Ko SM, Kim SH, Lee WY, et al. Imaging assessment of visceral pleural surface invasion by lung cancer: comparison of CT and contrast-enhanced radial T1-weighted gradient echo 3-Tesla MRI. Korean J Radiol 2021;22:829-39.

115. Bruzzi JF, Komaki R, Walsh GL, Truong MT, Gladish GW, Munden RF, et al. Imaging of non-small cell lung cancer of the superior sulcus: part 2. Initial staging and assessment of resectability and therapeutic response. Radiographics 2008;28:561-72.

116. Mihoubi Bouvier F, Thomas De Montpreville V, Besse B, Missenard G, Court C, Tordjman M, et al. Can MRI differentiate surrounding vertebral invasion from reactive inflammatory changes in superior sulcus tumor? Eur Radiol 2021;31:8991-9.

117. Peerlings J, Troost EG, Nelemans PJ, Cobben DC, de Boer JC, Hoffmann AL, et al. The diagnostic value of MR imaging in determining the lymph node status of patients with non-small cell lung cancer: a meta-analysis. Radiology 2016;281:86-98.

118. Takenaka D, Ohno Y, Hatabu H, Ohbayashi C, Yoshimura $\mathrm{M}$, Ohkita Y, et al. Differentiation of metastatic versus non-metastatic mediastinal lymph nodes in patients with non-small cell lung cancer using respiratory-triggered short inversion time inversion recovery (STIR) turbo spin-echo MR imaging. Eur J Radiol 2002;44:216-24.

119. Ohno Y, Hatabu H, Takenaka D, Higashino T, Watanabe H, Ohbayashi C, et al. Metastases in mediastinal and hilar lymph nodes in patients with non-small cell lung cancer: quantitative and qualitative assessment with STIR turbo spin-echo MR imaging. Radiology 2004;231:872-9.

120. Ohno Y, Koyama H, Nogami M, Takenaka D, Yoshikawa T, Yoshimura M, et al. STIR turbo SE MR imaging vs. coregistered FDG-PET/CT: quantitative and qualitative assessment of $\mathrm{N}$-stage in non-small-cell lung cancer patients. J Magn Reson Imaging 2007;26:1071-80.

121. Morikawa M, Demura Y, Ishizaki T, Ameshima S, Miyamori I, Sasaki M, et al. The effectiveness of 18F-FDG PET/ CT combined with STIR MRI for diagnosing nodal involvement in the thorax. J Nucl Med 2009;50:81-7.

122. Nomori H, Mori T, Ikeda K, Kawanaka K, Shiraishi S, Katahira $\mathrm{K}$, et al. Diffusion-weighted magnetic resonance imaging can be used in place of positron emission tomography for $\mathrm{N}$ staging of non-small cell lung cancer with fewer false-positive results. J Thorac Cardiovasc Surg 2008;135:816-22.

123. Hasegawa I, Boiselle PM, Kuwabara K, Sawafuji M, Sugi- ura $\mathrm{H}$. Mediastinal lymph nodes in patients with nonsmall cell lung cancer: preliminary experience with diffusion-weighted MR imaging. J Thorac Imaging 2008; 23:157-61.

124. Nakayama J, Miyasaka K, Omatsu T, Onodera Y, Terae S, Matsuno $\mathrm{Y}$, et al. Metastases in mediastinal and hilar lymph nodes in patients with non-small cell lung cancer: quantitative assessment with diffusion-weighted magnetic resonance imaging and apparent diffusion coefficient. J Comput Assist Tomogr 2010;34:1-8.

125. Usuda K, Zhao XT, Sagawa M, Matoba M, Kuginuki Y, Taniguchi $\mathrm{M}$, et al. Diffusion-weighted imaging is superior to positron emission tomography in the detection and nodal assessment of lung cancers. Ann Thorac Surg 2011; 91:1689-95.

126. Usuda K, Maeda S, Motono N, Ueno M, Tanaka M, Machida Y, et al. Diagnostic performance of diffusion-weighted imaging for multiple hilar and mediastinal lymph nodes with FDG accumulation. Asian Pac J Cancer Prev 2015; 16:6401-6.

127. Nomori H, Cong Y, Sugimura H, Kato Y. Diffusion-weighted imaging can correctly identify false-positive lymph nodes on positron emission tomography in non-small cell lung cancer. Surg Today 2016;46:1146-51.

128. Pauls S, Schmidt SA, Juchems MS, Klass O, Luster M, Reske SN, et al. Diffusion-weighted MR imaging in comparison to integrated [ $\left.{ }^{1} \mathrm{~F}\right]-\mathrm{FDG} \mathrm{PET} / \mathrm{CT}$ for $\mathrm{N}$-staging in patients with lung cancer. Eur J Radiol 2012;81:178-82.

129. Xu L, Tian J, Liu Y, Li C. Accuracy of diffusion-weighted (DW) MRI with background signal suppression (MR-DWIBS) in diagnosis of mediastinal lymph node metastasis of nonsmall-cell lung cancer (NSCLC). J Magn Reson Imaging 2014;40:200-5.

130. Wu LM, Xu JR, Gu HY, Hua J, Chen J, Zhang W, et al. Preoperative mediastinal and hilar nodal staging with diffusion-weighted magnetic resonance imaging and fluorodeoxyglucose positron emission tomography/computed tomography in patients with non-small-cell lung cancer: which is better? J Surg Res 2012;178:304-14.

131. Shen G, Lan Y, Zhang K, Ren P, Jia Z. Comparison of 18F-FDG PET/CT and DWI for detection of mediastinal nodal metastasis in non-small cell lung cancer: a meta-analysis. PLoS One 2017;12:e0173104.

132. Yi CA, Shin KM, Lee KS, Kim BT, Kim H, Kwon OJ, et al. Non-small cell lung cancer staging: efficacy comparison of integrated PET/CT versus 3.0-T whole-body MR imaging. Radiology 2008;248:632-42. 
133. Giesel FL, Heussel CP, Lindner T, Rohrich M, Rathke H, Kauczor HU, et al. FAPI-PET/CT improves staging in a lung cancer patient with cerebral metastasis. Eur J Nucl Med Mol Imaging 2019;46:1754-5.

134. Hicks RJ, Roselt PJ, Kallur KG, Tothill RW, Mileshkin L. FAPI PET/CT: will it end the hegemony of 18F-FDG in oncology? J Nucl Med 2021;62:296-302.

135. Yi CA, Lee KS, Lee HY, Kim S, Kwon OJ, Kim H, et al. Coregistered whole body magnetic resonance imaging-positron emission tomography (MRI-PET) versus PET-computed tomography plus brain MRI in staging resectable lung cancer: comparisons of clinical effectiveness in a randomized trial. Cancer 2013;119:1784-91.

136. Huellner MW, de Galiza Barbosa F, Husmann L, Pietsch CM, Mader CE, Burger IA, et al. TNM staging of non-small cell lung cancer: comparison of PET/MR and PET/CT. J Nucl Med 2016;57:21-6.

137. Lee SM, Goo JM, Park CM, Yoon SH, Paeng JC, Cheon GJ, et al. Preoperative staging of non-small cell lung cancer: prospective comparison of PET/MR and PET/CT. Eur Radiol 2016;26:3850-7.

138. Ohno Y, Koyama H, Nogami M, Takenaka D, Yoshikawa T, Yoshimura M, et al. Whole-body MR imaging vs. FDG-PET: comparison of accuracy of M-stage diagnosis for lung cancer patients. J Magn Reson Imaging 2007;26:498-509.

139. von Groote-Bidlingmaier F, Koegelenberg CF, Bolliger CT. Functional evaluation before lung resection. Clin Chest Med 2011;32:773-82.

140. van Tilburg PM, Stam H, Hoogsteden HC, van Klaveren RJ. Pre-operative pulmonary evaluation of lung cancer patients: a review of the literature. Eur Respir J 2009;33: 1206-15.

141. Ohno Y, Hatabu H, Higashino T, Takenaka D, Watanabe H, Nishimura $Y$, et al. Dynamic perfusion MRI versus perfusion scintigraphy: prediction of postoperative lung function in patients with lung cancer. AJR Am J Roentgenol 2004;182:73-8.

142. Ohno Y, Koyama H, Nogami M, Takenaka D, Matsumoto S, Yoshimura $\mathrm{M}$, et al. Postoperative lung function in lung cancer patients: comparative analysis of predictive capability of MRI, CT, and SPECT. AJR Am J Roentgenol 2007;189:400-8.

143. Ohno Y, Seki S, Koyama H, Yoshikawa T, Matsumoto S, Takenaka D, et al. 3D ECG- and respiratory-gated non-contrast-enhanced (CE) perfusion MRI for postoperative lung function prediction in non-small-cell lung cancer patients: a comparison with thin-section quantitative com- puted tomography, dynamic CE-perfusion MRI, and perfusion scan. J Magn Reson Imaging 2015;42:340-53.

144. Edelman RR, Hatabu H, Tadamura E, Li W, Prasad PV. Noninvasive assessment of regional ventilation in the human lung using oxygen-enhanced magnetic resonance imaging. Nat Med 1996;2:1236-9.

145. Ohno Y, Hatabu H, Higashino T, Nogami M, Takenaka D, Watanabe $\mathrm{H}$, et al. Oxygen-enhanced MR imaging: correlation with postsurgical lung function in patients with lung cancer. Radiology 2005;236:704-11.

146. Cerfolio RJ, Allen MS, Deschamps C, Trastek VF, Pairolero PC. Postoperative chylothorax. J Thorac Cardiovasc Surg 1996;112:1361-5.

147. Shah RD, Luketich JD, Schuchert MJ, Christie NA, Pennathur A, Landreneau RJ, et al. Postesophagectomy chylothorax: incidence, risk factors, and outcomes. Ann Thorac Surg 2012;93:897-903.

148. Yang DJ, Ren GS, Wang XY. Bilateral chylothorax following left supraclavicular lymph node dissection for breast cancer: one case report and literature review. Chin J Cancer 2014;33:317-20.

149. Bryant AS, Minnich DJ, Wei B, Cerfolio RJ. The incidence and management of postoperative chylothorax after pulmonary resection and thoracic mediastinal lymph node dissection. Ann Thorac Surg 2014;98:232-5.

150. Cho HJ, Kim DK, Lee GD, Sim HJ, Choi SH, Kim HR, et al. Chylothorax complicating pulmonary resection for lung cancer: effective management and pleurodesis. Ann Thorac Surg 2014;97:408-13.

151. Clement O, Luciani A. Imaging the lymphatic system: possibilities and clinical applications. Eur Radiol 2004;14: 1498-507.

152. Matsumoto T, Yamagami T, Kato T, Hirota T, Yoshimatsu R, Masunami T, et al. The effectiveness of lymphangiography as a treatment method for various chyle leakages. Br J Radiol 2009;82:286-90.

153. Silvestri RC, Huseby JS, Rughani I, Thorning D, Culver $\mathrm{BH}$. Respiratory distress syndrome from lymphangiography contrast medium. Am Rev Respir Dis 1980;122:5439.

154. Krishnamurthy R, Hernandez A, Kavuk S, Annam A, Pimpalwar S. Imaging the central conducting lymphatics: initial experience with dynamic MR lymphangiography. Radiology 2015;274:871-8.

155. Kim EY, Hwang HS, Lee HY, Cho JH, Kim HK, Lee KS, et al. Anatomic and functional evaluation of central lymphatics with noninvasive magnetic resonance lymphangiog- 
raphy. Medicine (Baltimore) 2016;95:e3109.

156. Hsu MC, Itkin M. Lymphatic anatomy. Tech Vasc Interv Radiol 2016;19:247-54.

157. Hyun D, Lee HY, Cho JH, Kim HK, Choi YS, Kim J, et al. Pragmatic role of noncontrast magnetic resonance lymphangiography in postoperative chylothorax or cervical chylous leakage as a diagnostic and preprocedural planning tool. Eur Radiol 2022;32:2149-57.

158. Chen S, Tan X, Wu R, Xu Y, Yang C, Wang M, et al. Non-enhanced MR lymphography of the thoracic duct: improved visualization following ingestion of a high fat meal-initial experience. Clin Physiol Funct Imaging 2017;37:730-3.

159. Jagoda P, Fleckenstein J, Sonnhoff M, Schneider G, Ruebe $\mathrm{C}$, Buecker $\mathrm{A}$, et al. Diffusion-weighted MRI improves response assessment after definitive radiotherapy in patients with NSCLC. Cancer Imaging 2021;21:15.

160. Runge VM. Safety of approved MR contrast media for intravenous injection. J Magn Reson Imaging 2000;12:20513.

161. Brockow K, Ring J. Classification and pathophysiology of radiocontrast media hypersensitivity. Chem Immunol Allergy 2010;95:157-69.

162. Kodzwa R. ACR manual on contrast media: 2018 updates. Radiol Technol 2019;91:97-100.

163. Lee SY, Lim KW, Chang YS. Radiocontrast media hypersensitivity in the Asia Pacific region. Asia Pac Allergy 2014; 4:119-25.

164. Kim J, Ryu SY, Lee SH, Lee HY, Park H. Clustering approach to identify intratumour heterogeneity combining FDG PET and diffusion-weighted MRI in lung adenocarcinoma. Eur Radiol 2019;29:468-75.

165. European Society of Radiology (ESR). White paper on imaging biomarkers. Insights Imaging 2010;1:42-5.

166. European Society of Radiology (ESR). Medical imaging in personalised medicine: a white paper of the research committee of the European Society of Radiology (ESR). Insights Imaging 2015;6:141-55.

167. Dregely I, Prezzi D, Kelly-Morland C, Roccia E, Neji R, Goh
V. Imaging biomarkers in oncology: basics and application to MRI. J Magn Reson Imaging 2018;48:13-26.

168. Nguyen ET, Bayanati H, Bilawich AM, Tijmes FS, Lim R, Harris S, et al. Canadian Society of Thoracic Radiology/ Canadian Association of Radiologists clinical practice guidance for non-vascular thoracic MRI. Can Assoc Radiol J 2021;72:831-45.

169. Lee G, Bak SH, Lee HY, Choi JY, Park H, Lee SH, et al. Measurement variability in treatment response determination for non-small cell lung cancer: improvements using radiomics. J Thorac Imaging 2019;34:103-15.

170. Raptis CA, Ludwig DR, Hammer MM, Luna A, Broncano J, Henry TS, et al. Building blocks for thoracic MRI: challenges, sequences, and protocol design. J Magn Reson Imaging 2019;50:682-701.

171. Lustig M, Donoho D, Pauly JM. Sparse MRI: the application of compressed sensing for rapid MR imaging. Magn Reson Med 2007;58:1182-95.

172. Wild JM, Stewart NJ. Chan HF. Hyperpolarised Helium-3 (3He) MRI: physical methods for imaging human lung function. In: Kauczor HU, Wielputz MO, editors. MRI of the lung. 2nd ed. Cham (CH); Springer; 2018. p. 69-97.

173. Qing K, Altes TA, Tustison NJ, Feng X, Chen X, Mata JF, et al. Rapid acquisition of helium-3 and proton three-dimensional image sets of the human lung in a single breathhold using compressed sensing. Magn Reson Med 2015; 74:1110-5.

174. Collier GJ, Wild JM. In vivo measurement of gas flow in human airways with hyperpolarized gas MRI and compressed sensing. Magn Reson Med 2015;73:2255-61.

175. van Leeuwen KG, Schalekamp S, Rutten M, van Ginneken $\mathrm{B}$, de Rooij M. Artificial intelligence in radiology: 100 commercially available products and their scientific evidence. Eur Radiol 2021;31:3797-804.

176. Gonem S, Janssens W, Das N, Topalovic M. Applications of artificial intelligence and machine learning in respiratory medicine. Thorax 2020;75:695-701. 